\title{
Evaluation of reaction between 2,4-Thiazolidinedione and p- Methoxybenzaldehyde in microreactors for production of drugs for treatment of Diabetes mellitus type 2
}

\author{
Rodrigo de Oliveira Vieira ${ }^{1}$, Harrson Silva Santana ${ }^{2 *}$, João Lameu Silva Jr. ${ }^{3}$, \\ Paula Almeida Meira ${ }^{1}$, Gabriel Lima Bressan ${ }^{1}$, Osvaldir P. Taranto ${ }^{2}$, Paulo Victor \\ Cuesta Calvo $^{1}$ and Mauri S. A. Palma ${ }^{1 * *}$ \\ 1. Department of Biochemical and Pharmaceutical Technology, São Paulo University, \\ Zip Code 05508-000, São Paulo, SP, Brazil. \\ 2. School of Chemical Engineering, University of Campinas, Zip Code 13083-852 \\ Campinas, SP, Brazil. \\ 3. Federal University of ABC, CECS - Centro de Engenharia, Modelagem e Ciências \\ Sociais, Alameda da Universidade, s/n., 09606-045, São Bernardo do Campo, SP, \\ Brazil.
}

\begin{abstract}
The use of microreactors in chemical and pharmaceutical industries allow a series of advantages due to their reduced sizes regarding conventional batch reactors. In the present paper the transposition of the reaction between 2,4-Thiazolidinedione with p-Methoxybenzaldehyde from batch to a continuous capillary microreactor was carried out. The microdevice performance was evaluated experimentally and numerically by CFD. The batch process yield $92 \%$ in 480 min using piperidine $(0.053 \mathrm{M})$ for equimolar reactant feed at $0.066 \mathrm{M}$, while the pyrrolidine promoted a $100 \%$ yield in a $50 \mathrm{~min}$ batch, both using solvent ethanol. Kinetic and thermodynamic parameters of the synthesis using piperidine and pyrrolidine were also obtained from experimental data. In the transposition to flow chemistry, ethanol was also used as solvent and a product yield of $100 \%\left(140{ }^{\circ} \mathrm{C}\right.$, pyrrolidine $)$ was obtained for a residence time of 20 minutes, representing a reduction of 24 times in the reaction time. The CFD simulations predicted an increment in conversion and yield with temperature corresponding to experiments with superior results at $140^{\circ} \mathrm{C}$. The smaller error between numerical results and experimental data was $3.1 \%$.
\end{abstract}

Keywords: microreactors; medicine drugs; diabetes; process intensification; numerical simulation; computational fluid dynamics.

*Corresponding author, E-mail address: harrison.santana@gmail.com;

harrson@unicamp.br (Harrson Santana);** msapalma@usp.br (Mauri Palma) 


\section{Introduction}

The evolution in chemical and pharmaceutical industries and the global necessity of sustainable methods providing processes less aggressive to environment, increasingly obligates the reduction of non-renewable natural resources consumption, as well, the decrease of waste generation. One of the hard stages to release a new synthetic medicine obtained in lab scale is the scale-up procedure to commercial demand, since it usually results in difficulties on mixing of reactants and heat and mass transfer inefficiencies [1]. In order to overcome these issues, the microreactors use has grown. These microdevices are composed by channels in microscale where low amounts of reactants flow and react for a determined time. The microscale results in an interesting alternative to conventional macroscale equipment [2], once the small length scales results in high conversion and selectivity inherent from the high surface area to volume ratio, enhancing heat and mass transfer rates. In addition, due to the reduced reaction volume, microreactor provide less waste generation, resulting in smaller environmental impact and low costs of effluent treatment [3].

Another advantage of microdevices is the production throughput, since the microreactors (MRs) operate in continuous flow, without parades for load and unload, or even for cleaning at each batch feed. Furthermore, MRs production can be superior than batch reactors. The increment of production rate is simpler, usually carried out by scaling-up the reactor volume that is an issue in conventional scales due to the difficulty to keep efficient heat transfer and agitation. The increment on production rate of MRs can be accomplished by the parallelization of microdevice units (numbering-up) keeping the transport phenomena characteristics of the individual MR $[4,5]$. Accordingly, complex industrial processes, often impracticable, could become feasible with Microreactor Technology (MRT). Furthermore, MRT allow processes with 
superior safety and easy automation and control. Due to the inherent reduce size, the process variables are easily controlled, such as flow rate, temperature and pressure. The reduced reactor volume allows the handling of explosive materials or with higher heat release, with superior safety that would be impossible to perform in a conventional batch reactor [6]. These characteristics have been draw attention of chemical and pharmaceutical industries, aiming the optimization of processes for synthesis of active and intermediate principles used in disease treatment, including diabetes.

The 2,4-thiazolidinedione (TZD) have been studied and applied due to its action affecting genes. This feature results in different biological activities by the molecule. Currently, the relationship of biological effects induce by the derivatives of TZD is far away to be completely understood. Some biological activities already verified possess great breakthroughs on medical area, including the action on diabetes mellitus type II, as well as the properties of antibacterial, anti-inflammatory, antioxidant, antifungal, anticonvulsant, anti-ischemic and anti-HIV [7,8,9]. In this context, chemistry and pharmaceutical professionals have been encouraged to perform molecular modification to use TZD on synthesis of several compounds with important pharmaceutical and therapeutic activities [8]. The use of MRs on research and synthesis of TZD derivatives in a fundamental-key, once MRs allow a faster and efficient production, using lower production inputs for an active principle for treating diabetes mellitus type II, one of the diseases of major preoccupation [10].

Once the drug synthesis is successful completed, the next step is the scale-up. Difficulties were related in the scale-up procedure from the microdevice volume increment to industrial scale. The main issues are related to the transport phenomena. Recent researches approached additional efforts for numbering-up procedure, e.g., flow rate distribution at each microdevice parallelized in the chemical plant [11]. For 
instance, considering a biodiesel plant with a capacity of $2000 \mathrm{~L} \mathrm{day}^{-1}$ [12], $3.4 \times 10^{6}$ microreactor units operating at $5.8 \times 10^{-4} \mathrm{~L} \mathrm{~min}^{-1}$ would be necessary [13]. The elevated number of microdevices is related to the micrometric dimensions and consequently, low flow rate. Fortunately, recent papers about microdevices scale-up exposed some interesting strategies for such procedure. Recently, our research group showed that the use of Computational Fluid Dynamics (CFD) - a numerical technique used in analyses of flow system and associated phenomena - allows the design of microfluidic devices with flow throughput up to 100 times larger than the currently available without lowering mass transfer and chemical reaction efficiencies. The microdevice dimensions were increased 100 times, equivalent to increase the flow rate at the same proportion [14]. The scaled-up microdevices design procedure starts with the numerical simulation of the flow pattern, then a geometry optimization was carried out. After this, the microdevice manufacturing was performed. One of the main steps in the microdevice development using CFD is the mathematical modeling, which must represent reliably the real physicochemical process [2].

Accordingly, the present research evaluated for the first time the reaction between TZD and p-Methoxybenzaldehyde in ethanol, generating the compound with potential biological action against diabetes mellitus type II. The synthesis was studied in conventional batch reactor and microreactors. The efficiency and viability of MRs usage for the intermediate pharmaceutical active production was assessed. The optimized operating conditions were obtained for the batch reactor (processing time) and microreactor (residence time), the promoter base selection and optimal concentration was also performed, in order to maximize reactants conversion and reaction yield.

The reactor performance was compared using the parameter of equivalent number of microreactor, $\mathrm{n}^{\circ} \mathrm{MR}$ [15], defined as the number of microreactors required to 
provide the same mass amount of a standard batch output. Furthermore, reaction rate constant, activation energy and thermodynamic parameters of transition state (enthalpy $\Delta H^{*}$, entropy $\Delta S^{*}$ and Gibbs free energy $\Delta G^{*}$ ) were also obtained. Considering the acquired data, computational fluid dynamic simulations were carried out, allowing obtaining a computational methodology to be used for a fast increment of production from microreactor to industrial demand.

\section{Experimental}

\subsection{Materials}

Thiourea (99.0\%, PA), Chloroacetic Acid (99.0\%, PA), Hydrochloric Acid (36.5\% to $38.0 \%$, PA), Ethanol (99.8\%, PA), Purified Water, 2,4-thiazolidinedione (TZD), p-methoxybenzaldehyde (99.8\%, PA), Piperidine (99.0\%, PA) and Pyrrolidine (> 99.0\%, PA). All chemicals were purchased from Sigma-Aldrich/Merck (Darmastadt, Germany) and Labsynth (Diadema, SP, Brazil) and were not previously purified. Only TZD was synthesized in the laboratory, with adapted methodology described in [16].

\subsection{Equipment and synthesis procedure}

The standard solutions were prepared by the addition of 4 mmol of TZD and 30 $\mathrm{mL}$ of solvent in a $100 \mathrm{~mL}$ flask (Solution 1). In another flask, $4 \mathrm{mmol}$ of $\mathrm{p}$ methoxybenzaldehyde with $30 \mathrm{~mL}$ of solvent (Solution 2). Solution 1 was maintained under agitation by $30 \mathrm{~min}$ at $30^{\circ} \mathrm{C}$ to ensure the total dissolution of TZD. Following, a $30 \mu \mathrm{L}$ sample was added in a vial with $1500 \mu \mathrm{L}$ of reaction inhibitor solution $(993.4 \mathrm{~mL}$ $\mathrm{ACN} / \mathrm{H}_{2} \mathrm{O}(50 / 50)+6.6 \mathrm{~mL}$ glacial acetic acid). Solution 2 was maintained in agitation under room temperature to ensure the complete dissolution of p-methoxybenzaldehyde. 
The batch reaction was carried out using a 3-necks round bottom balloon of 125 $\mathrm{mL}$ fixed over a warming blanket. Also, an Allihn condenser was allocated in the central neck. In the lateral necks a thermometer and a Medax (model Chiba 18G x 200 mm, Alpharad, Santo André, SP, Brazil) needle, were inserted with corks. The solution 1 and 2 were transferred to the batch reactor for heating up to the mixture boiling point, when the reaction base was added. Then, samples were collected at 2, 4, 8, 12, 16, 20, $50,80,180,330,480 \mathrm{~min}$, for reaction synthesis using piperidine, and at 2, 4, 8, 12, 16, 20, 30, 50, 70, 100, $130 \mathrm{~min}$ for pyrrolidine base. All samples were analyzed in a HPLC-UV, model Prominence 20 AD (Shimadzu, Kyoto, Japan) equipped with a C18 (5 $\mu \mathrm{m} \times 25 \mathrm{~cm})$ chromatographic column model Ascentis (Sigma-Aldrich/Merck, Darmstadt, Germany). The product quantification, as well, its purification procedure was detailed in Supplementary Material (Sections S.1 and S.2).

The product 5-(4-methoxybenzylidene)-2,4-thiazollidinedione (MBT) was synthesized from the reaction of TZD with p-methoxybenzaldehyde in a capillary microreactor apparatus equipped with a Asia pump of two channels with chip headstocks, syringes and tubes 110 for Asia and two capillary microreactors with internal volume of $1000 \mu \mathrm{L}$, a back pressure regulator and a heat system composed by a heat plate with magnetic agitation and a glass beaker filled with $1 \mathrm{~L}$ of silicon oil. The temperature was adjusted using a thermometer immersed into oil. The MBT synthesis in the microreactor was performed with the same reactant concentration and promoter base used in batch process. The solution preparation and MBT synthesis schematics are presented in Figure 1. 


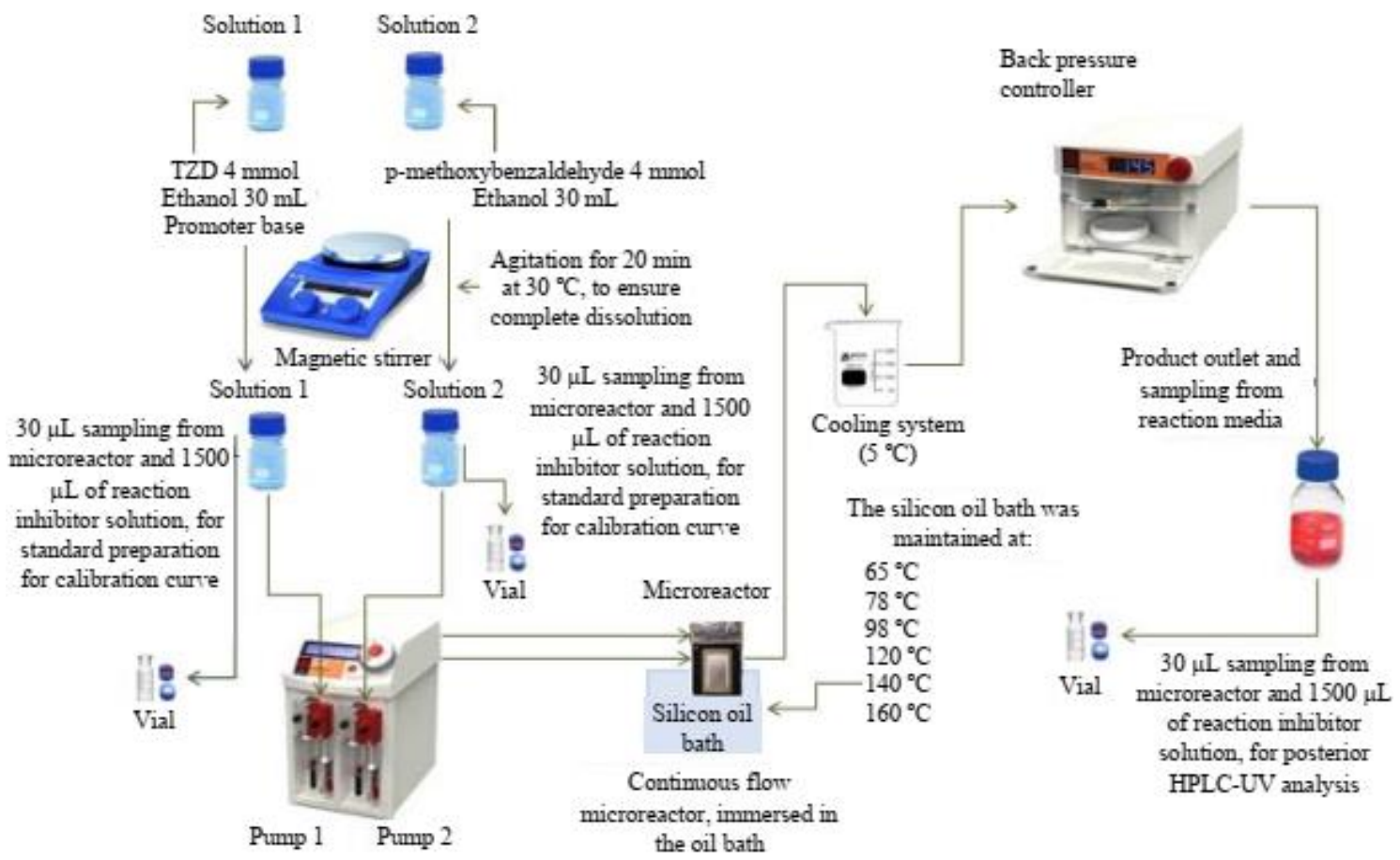

Figure 1. Flowchart of reaction media preparation and MBT synthesis in the microreactor.

Firstly, two pumps (P1 and P2) were initialized, in order to transport the solutions towards the two capillary microreactors arranged in series. Two suction tubes, equipped with filter at inlets, were inserted in a flask container filled with $50 \mathrm{~mL}$ of ethanol $(99.8 \%)$ and the heating system was switched on. The suction pipes were completely filled with ethanol (cleaning solvent) and the absence of bubbles was checked. Then, the pumps P1 and P2 were adjusted to $500 \mu \mathrm{L} / \mathrm{min}$, resulting in a total flow rate of $1000 \mu \mathrm{L} / \mathrm{min}$ and was awaited the system required temperature and pressure.

The pressure was controlled according to Table 1, summarizing the minimum and operation pressure for each temperature, in order to avoid solvent evaporation during the experimental runs, allowing also the evaluation at operating temperatures above the normal boiling point. 
Table 1. Temperature, minimum and operating pressure for liquid state reaction.

Solvent: Ethanol

\begin{tabular}{c|c|c}
\hline Temperature $\left({ }^{\circ} \mathrm{C}\right)$ & Minimum pressure (bar) & Operating pressure (bar) \\
\hline 78 & 0.1 & 1.1 \\
98 & 2.0 & 3.0 \\
120 & 3.2 & 4.2 \\
140 & 6.3 & 7.3 \\
160 & 10.7 & 11.7 \\
\hline
\end{tabular}

Under the required temperature and pressure, the ethanol container was replaced by the solution 1 and 2 flasks, using pumps P1 and P2, respectively. For the operation at $1000 \mu \mathrm{L} / \mathrm{min}$ (first run), the first $8 \mathrm{~min}$ of the run was defined as a reject time to ensure that the initial ethanol (cleaning solvent) was discarded from the microreactors and the reaction media filled the microreactors (about $8 \mathrm{~mL}$, from the flasks 1 and 2 , to the sampling tube at the second microreactor outlet). For the subsequent runs the reject time are listed in Table S1 (Section S.3). The reject time is necessary to avoid the interference of results for subsequent runs, ensuring the completely discharge of the reaction media from the previous run. The reject time from second run is different from 8 min, since in such runs only the residual reaction media must be discarded. Table S1 also summarized the flow rates of the microreactor runs.

Sampling was performed collecting 10 droplets from the MR outlet in $5 \mathrm{~mL}$ test tubes. Accordingly, $30 \mu \mathrm{L}$ were collected and added in vials containing $1500 \mu \mathrm{L}$ of reaction inhibitor solution (993.4 $\mathrm{mL} \mathrm{ACN} / \mathrm{H}_{2} \mathrm{O}(50 / 50)+6.6 \mathrm{~mL}$ glacial acetic acid), and then sent to HPLC-UV analyses. The longer residence time evaluated was $30 \mathrm{~min}$, considered a reasonable time for microreactor runs, providing relevant experimental data of reactant conversion and product yield. 


\subsection{Analytical methods and data treatment}

The following analytical methods were employed in the characterization and quantification of MBT: melting point determination; Fourier-transform infrared spectroscopy (FT-IR); High Performance Liquid Chromatography (HPLC-UV); Nuclear Magnetic Resonance Spectrometer (NMR); Differential Scanning Calorimetry (DSC).

Data treatment was performed as the following procedures: quantification of limiting reactant conversion, desired product (MBT) yield, initial reaction rate, production rate and equivalent number of microreactors. The conversion, $X_{A}$, of the generic reaction $a A+b B \rightarrow p P+q Q$, was defined as the limiting reactant fraction consumed in the reaction determined by Eq. $1[17,18]$ :

$X_{A}=\frac{C_{A 0}-C_{A}}{C_{A 0}}$

Where $C_{A O}$ and $C_{A}$ are the initial and final concentrations of the limiting reactant, respectively.

The desired product $\mathrm{P}$ yield, $Y_{P}$, is quantified by its stoichiometric relationship of the amount of generated product to the amount of product in ideal conditions of no subproduct generation $[17,18]$, according to Eq. 2:

$Y_{P}=\frac{a\left(C_{P}-C_{P 0}\right)}{p C_{A 0}}$

Where $C_{P O}$ and $C_{P}$ are the initial and final concentrations of the desired product, respectively, $C_{A O}$ is the initial concentration of the limiting reactant and $a$ and $p$ are the stoichiometric coefficients of limiting reactant and desired product, respectively.

The initial reaction rate, $V_{i}$, was determined by Eq. 3, given as the ratio of the variation of product molar concentration $\left(\Delta C_{p}\right)$ by the time interval from the reaction beginning to the sampling time interval $(\Delta t)$ :

$V_{i}=\frac{\Delta \mathrm{C} p}{\Delta t}$ 
Where $C_{p}$ is the product molar concentration at instant $t\left(\mathrm{~mol} \mathrm{~L}^{-1}\right)$ and $\Delta t$ is the sampling time interval (min).

\subsubsection{Production rate and equivalent number of microreactors $\left(n^{0} M R\right)$}

The production rate from batch reactor and microreactor were calculated by Eqs. 4 and 5, respectively:

$$
\operatorname{Pr}^{\text {Batch }}=\frac{C_{\text {Final } x} V_{R}}{t_{\text {Batch }}}
$$

Where $C_{\text {Final }}$ is the product concentration at the final of batch $\left(\mathrm{g} \mathrm{L}^{-1}\right), V_{R}$ is the batch reactor volume $(\mathrm{L}), t_{\text {Batch }}$ is the batch time $(\mathrm{min})$ :

$\operatorname{Pr}^{M R}=Q_{\text {Total }} C_{\text {exit }}$

Where $Q_{\text {total }}$ is the total flow rate of microreactor $\left(\mathrm{L} \mathrm{min}^{-1}\right)$ and $C_{\text {exit }}$ is the product concentration at outlet $\left(\mathrm{g} \mathrm{L}^{-1}\right)$.

In order to quantify the number of parallel microreactor units to achieve the same production rate estimated for the batch reactor, the number of equivalent microreactors $\left(n^{o} M R\right)$ was defined according to Eq. 6, given as the ratio of production rate of the batch to the continuous microreactor:

$n^{\circ} M R=\frac{P r^{B a t c h}}{\operatorname{Pr}^{M R}}$

Where $n^{o} M R$ is the number of equivalent microreactors, $P r^{B a t c h}$ is the batch production rate $\left(\mathrm{mg} \mathrm{min}^{-1}\right)$ and $P r^{M R}$ is the continuous microreactor production rate $\left(\mathrm{mg} \mathrm{min}^{-1}\right)$.

\subsubsection{Determination of kinetic data and thermodynamic parameters}

The reaction order for each reactant was determined by the excess method. The obtained data was adjusted by the integral method analyzing the first order model ( $r=$ $k C_{A}$ ), according to $\mathrm{Eq} 7$ :

$-\ln \frac{\mathrm{C}_{\mathrm{A}}}{\mathrm{C}_{\mathrm{A} 0}}=\mathrm{kt}$ 
The global reaction order was evaluated by a second order model $\left(r=k C_{A} C_{B}\right)$, given by Eqs. 8 and 9:

$$
\begin{array}{ll}
\ln \frac{\mathrm{C}_{\mathrm{B}}}{\mathrm{C}_{\mathrm{A}}}=\ln \frac{\mathrm{C}_{\mathrm{B} 0}}{\mathrm{C}_{\mathrm{A} 0}}+\left(\mathrm{C}_{\mathrm{B} 0}-\mathrm{C}_{\mathrm{A} 0}\right) \mathrm{kt} & \left(C_{B 0} / C_{A 0} \neq 1\right) \\
\frac{1}{\mathrm{C}_{\mathrm{A}}}=\frac{1}{\mathrm{C}_{\mathrm{A} 0}}+\mathrm{kt} & \left(C_{B 0} / C_{A 0}=1\right)
\end{array}
$$

Where $\mathrm{C}_{A O}$ and $\mathrm{C}_{B O}$ are the initial concentration of TZD and p-methoxybenzaldehyde, respectively, $k$ is the second-order reaction constant and $t$ is the time.

The activation energy, $E_{a}$, was obtained from the Arrhenius model [18], given by Eq. 10:

$\mathrm{k}=\mathrm{k}_{0} \mathrm{e}^{-\frac{\mathrm{Ea}}{\mathrm{RT}}}$

Where $k$ is the second-order reaction constant $\left(\mathrm{L} \mathrm{mol}^{-1} \mathrm{~s}^{-1}\right), k_{0}$ is the frequency factor, related to the molecular collision $\left(\mathrm{L} \mathrm{mol}^{-1} \mathrm{~s}^{-1}\right), R$ is the ideal gas constant $(8.314$ $\mathrm{J} / \mathrm{mol} . \mathrm{K}), T$ is the absolute temperature $(\mathrm{K})$. The plot $\ln (k)$ versus $1 / T$ provides gives a slope $=-E a / R T$ and a linear coefficient of $\ln \left(k_{0}\right)$.

The variations of enthalpy, $\Delta H^{*}$, entropy, $\Delta S^{*}$, and Gibbs free energy $\Delta G^{*}$, were estimated from experimental data from the plot $\ln (k / T)$ versus $1 / T$, according to Eyring model, as given by Eq. 11 [18]:

$$
\ln \frac{k}{T}=\ln \frac{k_{B}}{h}+\frac{\Delta S^{*}}{R}-\frac{\Delta H^{*}}{R T}
$$

Where $k$ is the second-order reaction constant $\left(\mathrm{L} \mathrm{mol}^{-1} \mathrm{~s}^{-1}\right), k_{B}$ is the Boltzmann constant, $R$ is the ideal gas constant $(8.314 \mathrm{~J} / \mathrm{mol} . \mathrm{K}), T$ is the absolute temperature $(\mathrm{K})$, $h$ is the Planck constant $\left(6.63 \times 10^{-34} \mathrm{~J} . \mathrm{s}\right)$.

The plot slope allows the quantification of $\Delta H^{*}$ and the linear coefficient provides estimation of $\Delta S^{*}$. Accordingly, the $\Delta G^{*}$ was estimated from Eq. 12:

$\Delta G^{*}=\Delta H^{*}-T \Delta S^{*}$ 
The thermodynamic and kinetic parameters, $E_{a}, \Delta H^{*}, \Delta S^{*}$ and $\Delta G^{*}$, present a fundamental role to characterize the chemical reaction behavior and even for comparison with other chemical reactions. Currently, it was not found in literature the thermodynamic and kinetic parameters evaluated on the present research. From these data, the computational methodology was developed aiming the numerical study of the synthesis of 5-(4-methoxybenzylidene)-2,4-thiazollidinedione (MBT) in microreactors.

\section{Mathematical modeling and numerical simulation}

\subsection{Capillary microreactor geometry and numerical details}

The computational domain for the numerical simulation consisted in two microreactors of $1000 \mu \mathrm{L}$ (Asia, Syrris) [19]. Each microreactor presented a T-shape inlet, with a mixing and a reaction zone, as described in Figure 2. The definition of mixing and reaction zones followed the Syrris specification, however, in practice (experimental and numerically), the chemical reaction can occur in both zones. The microreactors have rectangular cross section of dimensions: $161 \mu \mathrm{m}$ x $1240 \mu \mathrm{m}$ x 536 mm (width $\mathrm{x}$ height $\mathrm{x}$ longitudinal length) in mixing zone and $391 \mu \mathrm{m} \times 1240 \mu \mathrm{m} \times$ $1844 \mathrm{~mm}$ (width $\mathrm{x}$ height $\mathrm{x}$ longitudinal length) in reaction zone.

The spatial discretization influence in numerical predictions was based on previous study, employing the characteristic size of discretization from the independent mesh used by [20]. The boundary conditions employed were: inlets: prescribed velocity and chemical species compositions; outlet: relative pressure zero (the absolute pressure was set in the reference pressure, according to Table 1); walls: no-slip velocity condition at solid surfaces. Steady-state numerical solutions were obtained using a RMS target of $1 \times 10^{-5}$ with a conservation target of 0.01 from a iteration range of 500150000 solved in parallel processing with Intel Xeon E5-2680v4, $2.4 \mathrm{GHz}$ installed in 
18 computational nodes with a total RAM of 2.24 TB with CentOS 64-bit operating system.

(a)

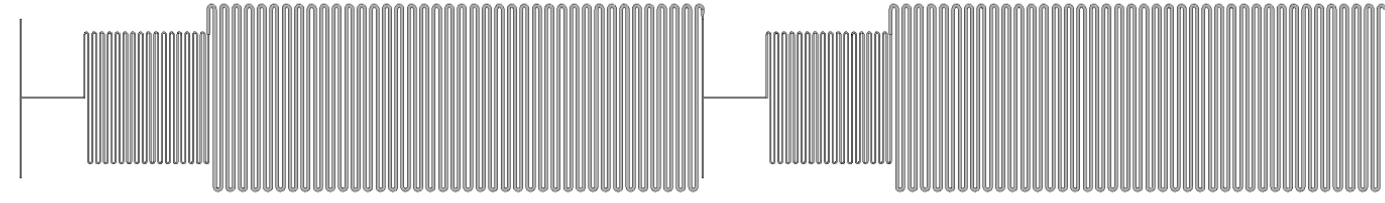

(b)

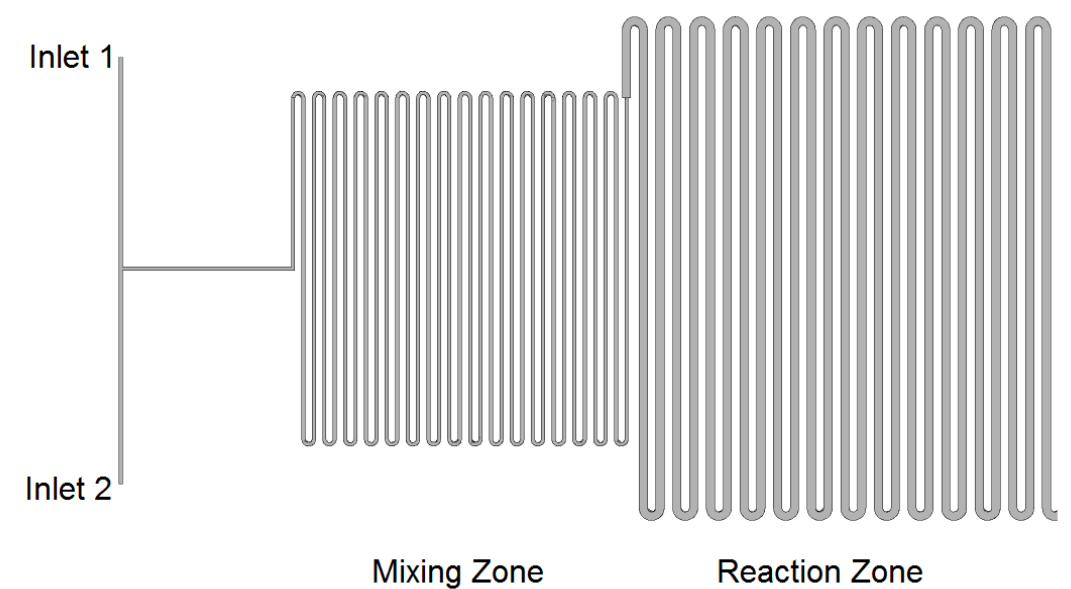

Figure 2. Details of microreactors used: (a) two microreactors arranged in series; (b) details of inlets and mixing and reaction zones of the microreactor.

\subsection{Mathematical modeling}

The simulations were accomplished using the computational code ANSYS CFX 19. In the present research, the equations of conservation of total mass (continuity) (Eq. 13), momentum (Navier-Stokes) (Eq. 14) and mass of chemical species (Eq. 15) were solved for incompressible, steady-state, isothermal and laminar flow conditions:

$$
\begin{aligned}
& \nabla \cdot U=0 \\
& \rho(U \cdot \nabla U)=-\nabla p+\mu \nabla^{2} U+\rho g \\
& \rho\left(U \cdot \nabla Y_{i}\right)=\rho D_{i} \nabla^{2} Y_{i}+S_{i}
\end{aligned}
$$


where $\rho$ is the specific mass $\left(\mathrm{kg} \mathrm{m}^{-3}\right), U$ is the velocity vector $\left(\mathrm{m} \mathrm{s}^{-1}\right), \mu$ is the dynamic viscosity ( $\mathrm{Pa} \mathrm{s}), g$ is the gravity acceleration $\left(\mathrm{m} \mathrm{s}^{-2}\right), p$ is the pressure $\left(\mathrm{kg} \mathrm{m}^{-1} \mathrm{~s}^{-2}\right), Y$ is the mass fraction, $D_{i}$ is the kinematic diffusion coefficient $\left(\mathrm{m}^{2} \mathrm{~s}^{-1}\right)$ and $S$ is the mass source due to chemical reactions $\left(\mathrm{kg} \mathrm{m}^{-3} \mathrm{~s}^{-1}\right)$, modeled in accordance with Eq. 16:

$S_{i}=\left(\sum_{r_{r}}^{n} v_{i}^{\prime \prime} r_{r}-\sum_{r_{r}}^{n} v_{i}^{\prime} r_{r}\right) M_{W i}$

where $M_{W}$ is the molecular weight, $v^{\prime \prime}$ e $v^{\prime}$ are the stoichiometric coefficient of the chemical species as products or as reactants, respectively, at the chemical reaction $r$ and $r_{r}$ is the rate of reaction $r$. The mass diffusion coefficient of chemical species were based on water-ethanol using the Wilke-Chang correlation [21], and for the other species, the mass diffusivity coefficients were estimated based on their viscosities using water-ethanol diffusion coefficient as reference.

For the studied synthesis, 2,4-thiazolidinedione (TZD) reacts with $p$ methoxybenzaldehyde (p-MTB) to produce (Z)-5-(4-methoxybenzylidene)thiazolidine2,4-dione (MBT) and water in a liquid phase catalytic reaction, according to the following global reaction:

$\mathrm{TZD}+\mathrm{p}-\mathrm{MTB} \longrightarrow \mathrm{MBT}+\mathrm{H}_{2} \mathrm{O}$

Pyrrolidine was used as promoter base and ethanol as solvent for both reactants. The molar mass of the chemical species were TZD $=117.12 \mathrm{~kg} \mathrm{kmol}^{-1} ; \mathrm{p}-\mathrm{MTB}=$ $136.15 \mathrm{~kg} \mathrm{kmol}^{-1}$; MBT $=235.25 \mathrm{~kg} \mathrm{kmol}^{-1}$ and $\mathrm{H}_{2} \mathrm{O}=18.02 \mathrm{~kg} \mathrm{kmol}^{-1}$. The mass sources due of chemical species due to the chemical reaction were defined based on the global reaction stoichiometry and on the global second order consumption rate:

$r=-k C_{T Z D} C_{p-M T B}$

The pyrrolidine effect on the reaction rate was included in the kinetic parameter $k$. The chemical species mass sources (Eqs. 15 and 16) are given by: 
$S_{T Z D}=-r M_{T Z D}$

$S_{p-M T B}=-r M_{p-M B T}$

$S_{M B T}=r M_{M B T}$

$S_{\mathrm{H}_{2} \mathrm{O}}=r M_{\mathrm{H}_{2} \mathrm{O}}$

The ethanol solvent was considered as a constraint to ensure the mass fraction restriction.

\section{Results and discussion}

\subsection{Synthesis of (Z)-5-(4-methoxybenzylidene)thiazolidine-2,4-dione (MBT) in the batch reactor}

\subsubsection{Study of the bases}

The chemical reaction studied on the present research is named Knoevenagel condensation and requires a promoter base to generate the desired product. According to literature, piperidine is the most commonly used base for such synthesis [9,22-24]. However, the Brazilian national agency of health surveillance, Agência Nacional de Vigilância Sanitária (ANVISA), controlled the use of piperidine and its derivatives and salts, complicating the importation and transportation of these substances. Consequently, big importation companies quit the piperidine commercialization. In this context, the search for new bases for the specific reaction motivated an extensive literature review and research about this issue. Based on the physicochemical properties of piperidine (standard base), the main goal was to found alternative promoter bases with similar characteristics for an efficient replacement on the synthesis.

Six amine bases were evaluated: morpholine, phenylethylamine, diaminoethane, propargylamine, piperazine and pyrrolidine. All reaction tests followed the same 
methodology applied to the reaction with piperidine, using ethanol as solvent. Three base concentrations were studied: $0.040 \mathrm{M}, 0.053 \mathrm{M}$ and $0.067 \mathrm{M}$, except for diaminoethane and pyrrolidine that were evaluated at $0.027 \mathrm{M}, 0.033 \mathrm{M}$ and $0.053 \mathrm{M}$, once concentrations above $0.053 \mathrm{M}$ resulted on MBT degradation, marked by a sharp decrease on yield.

The superior results of base concentration effect on reaction yield are provided by Figure 3. The suggested parameters used as performance criteria for base selection are summarized on Table 2.

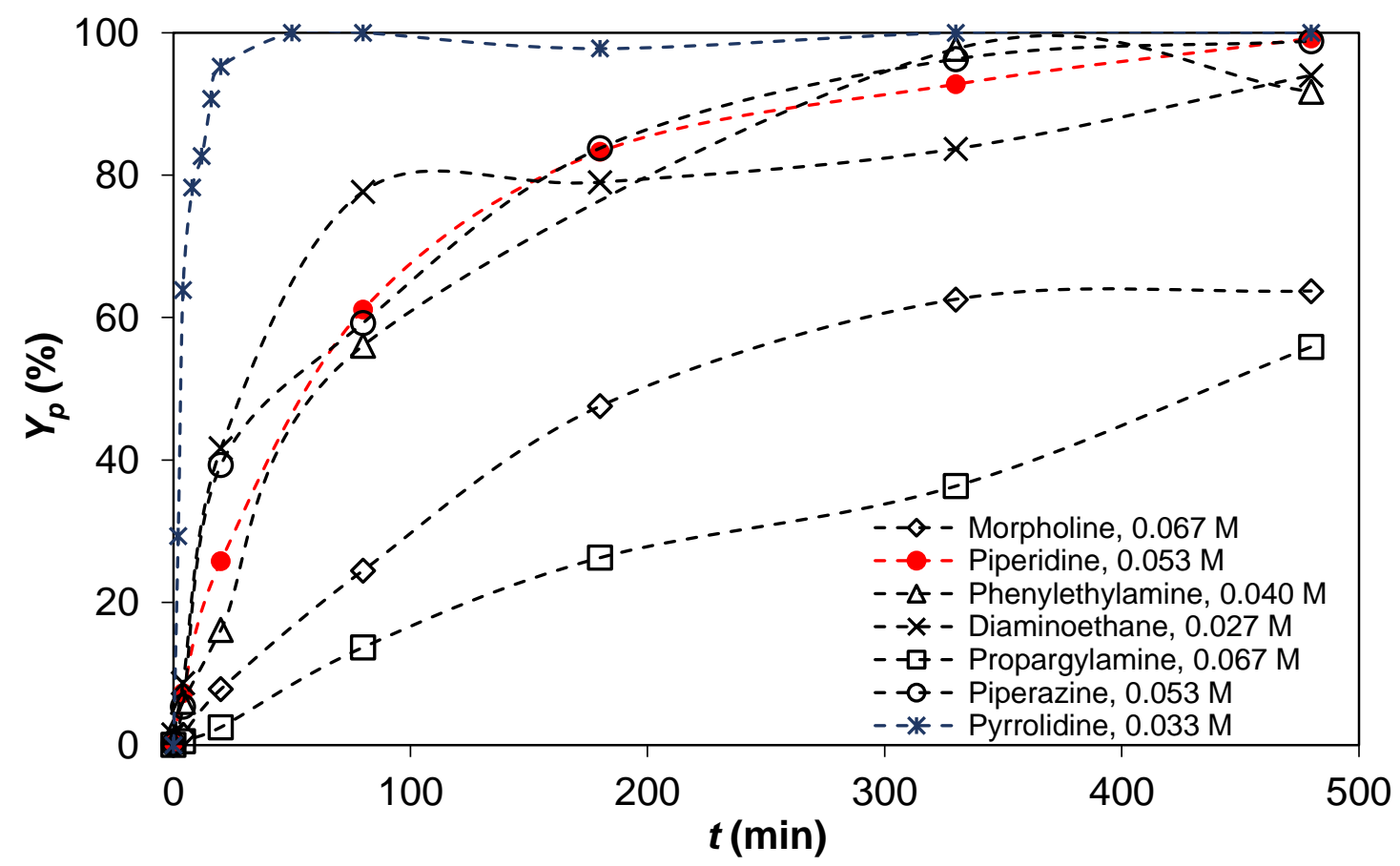

Figure 3. Reaction yield with different promoter bases in the batch reactor. Solvent: ethanol. $T=78^{\circ} \mathrm{C}$ (Reflux). 
Table 2. Characterization parameters for promoter base performance evaluation.

\begin{tabular}{cccc}
\hline Base & $\begin{array}{c}V_{\mathrm{i}, \mathrm{p}} \times 10^{3} \\
\left(\mathrm{~mol} \mathrm{~L}^{-1} \mathrm{~min}^{-1}\right)\end{array}$ & $\begin{array}{c}Y_{p, \text { máx }} \\
(\%)\end{array}$ & $\begin{array}{c}t_{Y p \text { máx }} \\
(\mathrm{min})\end{array}$ \\
\hline Piperidine & 1.09 & 92 & 480 \\
Pyrrolidine & $\mathbf{1 3 . 1}$ & $\mathbf{1 0 0}$ & $\mathbf{4 8 0}$ \\
Diaminoethane & 1.30 & 91 & 480 \\
Phenylethylamine & 0.90 & 89 & 480 \\
Piperazine & 1.18 & 95 & 480 \\
Morpholine & 0.23 & 65 & 480 \\
Propargylamine & 0.08 & 45 & 480
\end{tabular}

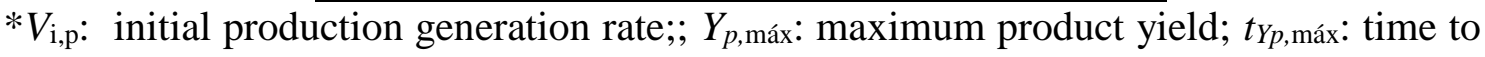
achieve the maximum reaction yield.

Figure 3 and Table 2 showed that pyrrolidine exhibited superior results for the analyzed parameters of initial production generation rate and maximum product yield, providing values of $13.1 \mathrm{~mol} \mathrm{~L}^{-1} \mathrm{~min}^{-1}$ and $100 \%$, respectively.

From the results of Figure 3 and Table 2 was noticed that three of the six evaluated bases presented satisfactory results: phenylethylamine, diaminoethane and piperazine, providing product yield of 89,91 e $95 \%$, respectively, in the reaction time of 480 min. Among these three bases, phenylethylamine presented an inferior initial generation rate of $0.90 \mathrm{~mol} \mathrm{~L}^{-1} \mathrm{~min}^{-1}$, while diaminoethane and piperazine provided values of 1.30 and $1.18 \mathrm{~mol} \mathrm{~L}^{-1} \mathrm{~min}^{-1}$, respectively. Morpholine and propargylamine exhibited poor performance, providing yields of 65 and $45 \%$ after $480 \mathrm{~min}$. Also, the initial generation rates were inferior for these two bases, as observed in Table 2.

A feasible explanation for such results is related to the conjugated acid $\mathrm{pKa}$ and the Van der Waals volume of the studied bases. The decrease of conjugated acid pKa means a basicity reduction, a fundamental characteristic to allow the synthesis by the Knoevenagel pathway. Thus, the inferior reaction yield, observed for morpholine and propargylamine, can be attributed to their lower values of conjugated acid pKa. 
However, not only the pKa affects the promoter base behavior, but also, the Van der Waals volume that is directly related to the steric hindering. The pKa and Van der Walls volume of the studied bases are given in Supplementary Information, Section S4.

Accordingly, pyrrodiline appears as a viable promoter base to replace piperidine in the chemical reaction of 2,4-thiazolidinedione (TZD) with $p$-methoxybenzaldehyde (p-MTB) to produce (Z)-5-(4-methoxybenzylidene)thiazolidine-2,4-dione (MBT) using ethanol as solvent.

\subsubsection{Study of reaction time and base concentration}

In the batch reactor runs, the processing time to achieve higher yields was determined, once from literature the batch time ranges from 20 to $40 \mathrm{~h}$, using the promoter base piperidine $0.053 \mathrm{M}$ and solvent ethanol $[9,22,24,25]$, and was not found studies verifying if these processing times were really necessary to complete the synthesis. This analysis was based on the results shown in Figure 3 and Table 2.

From the results was observed a $92 \%$ of product yield after 480 min using piperidine, showing that $8 \mathrm{~h}$ are adequate to perform the experimental runs, since an increment in processing time would not result in superior performance of the synthesis, contradicting the processing time range of 20-40 $\mathrm{h}$ found in literature.

As detailed in the previous section, pyrrolidine can replace piperidine as the promoter base (Table 2). Pyrrolidine provided superior initial reaction rate, achieving maximum product yield (100\%) after $480 \mathrm{~min}$.

Using solvent ethanol, a study of promoter base concentration was performed to verify the optimal concentration of $0.053 \mathrm{M}$ of piperidine (Section S5, Supplementary Information). The base concentration was varied $25 \%$ from the $0.053 \mathrm{M}$, i.e., $0.040 \mathrm{M}$ and $0.067 \mathrm{M}$. For the piperidine, the superior performance for the synthesis was observed at $0.053 \mathrm{M}$. A similar evaluation was carried out for pyrrolidine, as detailed in 
Supplementary Information, Section S5, and the optimal concentration found was 0.033 M.

\subsection{Synthesis of (Z)-5-(4-methoxybenzylidene)thiazolidine-2,4-dione (MBT) in the microreactor}

The MBT was synthesized in the microreactors using ethanol as solvent. The two better promoter bases, piperidine and pyrrolidine, were used to compare batch and flow chemistry processing, also to evaluate the performance of pyrrolidine on the continuous synthesis. Since the microreactor apparatus presents a safety pressure control, runs in temperatures above the solvent normal boiling point was also carried out, surpassing one of the batch reactor limitations. For this step, both, product yield and TZD conversion were quantified, since the use microreactors are recommended to determine the reaction kinetics [26,27].

Firstly, a Residence Time Distribution (RTD) study was performed to verify the plug flow ideality. The flow regime was laminar, due to the low Reynolds number inherent of the channel microscale size. The RTD procedure is detailed on Supplementary Information, Section S6 and the results were published in [28]. From the data presented in Section S6 was observed no significative differences between experimental data and theoretical model (step function), suggesting a low dispersion of the tracer, characterizing a plug flow. Experimental data slightly diverged from the step function, mostly at the beginning and ending of the step perturbation, evidencing a quasi-ideality of the flow and absence of preferred paths or dead zone along the microreactor channel.

\subsubsection{MBT synthesis}

After the definition of optimal conditions for MBT synthesis in batch reactor, the process was transposed to the microreactor to evaluate the continuous synthesis 
feasibility. Piperidine and pyrrolidine were employed. Experimental runs with residence times of 2, 4, 8, 12, 16 and 20 min were carried out and compared with batch process due to the plug flow behavior observed in the microdevice. The obtained results for TZD conversion and reaction yield using solvent ethanol and piperidine for the temperature range $78-160{ }^{\circ} \mathrm{C}$ are shown in Figures 4 and 5 .

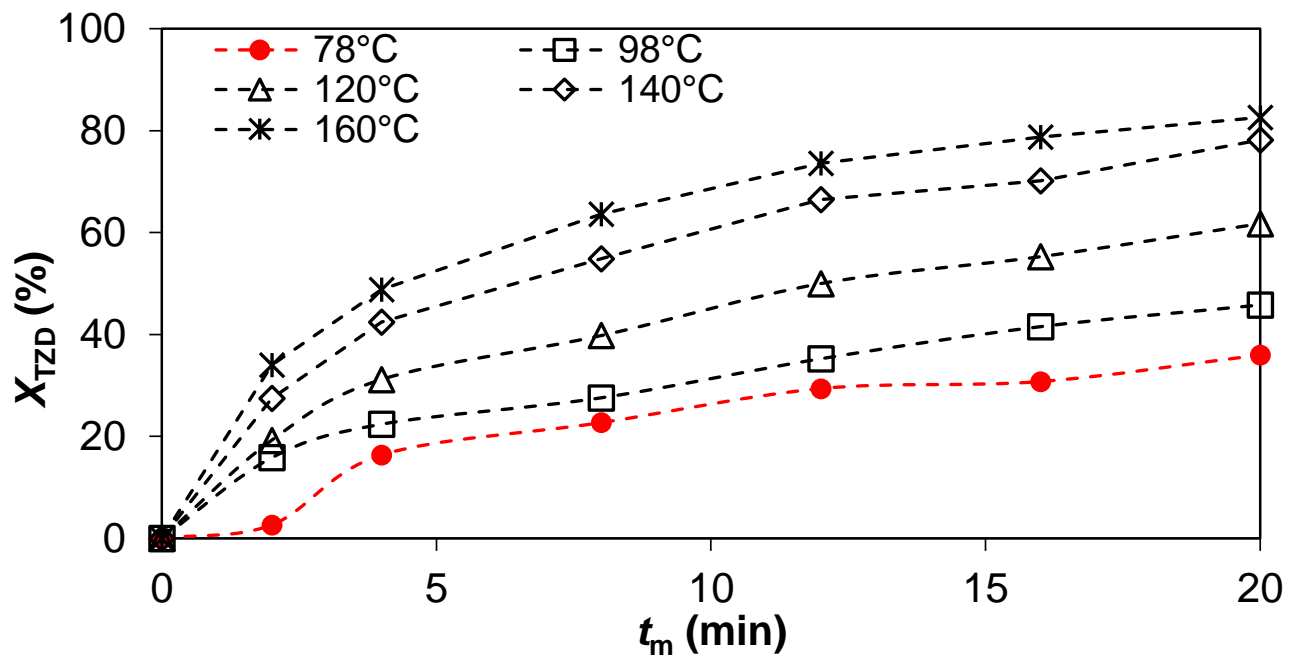

Figure 4. TZD conversion obtained from continuous microreactor process. Solvent: ethanol. Base: piperidine, $0.053 \mathrm{M}$.

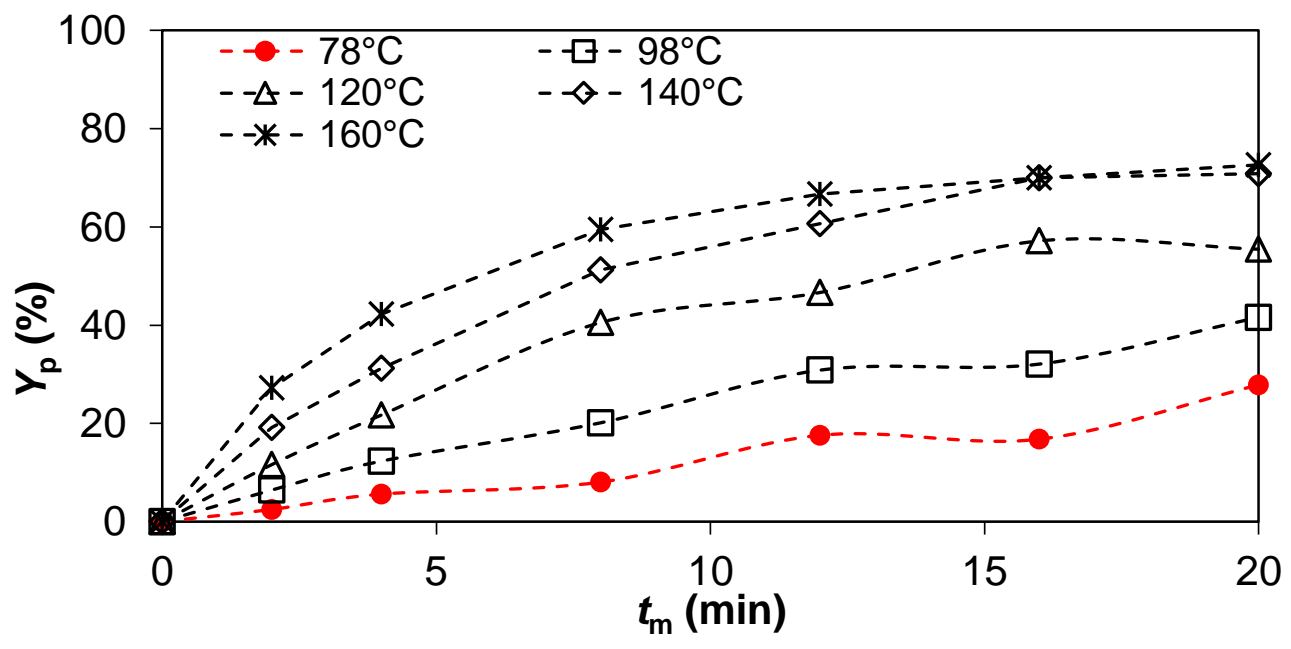


Figure 5. Reaction yield obtained from continuous microreactor process. Solvent: ethanol. Base: piperidine, $0.053 \mathrm{M}$.

Figures 4 and 5 highlight the importance of temperature on the synthesis, once a significative increment in TZD conversion and reaction yield was noticed. From Figure 5 , the reaction yields were $28,42,55,71$ and $72 \%$ for $78,98,120,140$ and $160{ }^{\circ} \mathrm{C}$, respectively, for $20 \mathrm{~min}$ of residence time. Same behavior was observed for TZD conversions (Figure 4), 36, 48, 63, 79 and 82\% for $78,98,120,140$ and $160{ }^{\circ} \mathrm{C}$, respectively, for $20 \mathrm{~min}$ of residence time. From the results presented in Figure 4 and 5, the increase on residence time also resulted in superior performance (reactant conversion and product yield increment). At $160^{\circ} \mathrm{C}$, the TZD conversions (Figure 4) were $34,49,64,73,79$ and $82 \%$ for $t_{\mathrm{m}}=2,4,8,12,16$ e $20 \mathrm{~min}$, respectively. For the same temperature, the reaction yields were (Figure 6) 27, 42, 59, 67, 70 and $72 \%$ for $t_{\mathrm{m}}$ $=2,4,8,12,16$ and $20 \mathrm{~min}$, respectively. The product yield was virtually equal at 140 ${ }^{\circ} \mathrm{C}$ and $160{ }^{\circ} \mathrm{C}$ for the residence times of 16 and $20 \mathrm{~min}$, about $70-72 \%$. This behavior suggests that the reaction temperature limit was achieved and values above $140{ }^{\circ} \mathrm{C}$ will not provide significative increment on yield.

Figures 6 and 7 presents the TZD conversion and product yield obtained in the microreactor using ethanol solvent with pyrrolidine. The residence times were $2,4,8$, $12,16,20,30,50$ and $70 \mathrm{~min}$, once a tendency of increment on conversion and yield was observed for residence times above $20 \mathrm{~min}$, regarding the piperidine runs. 


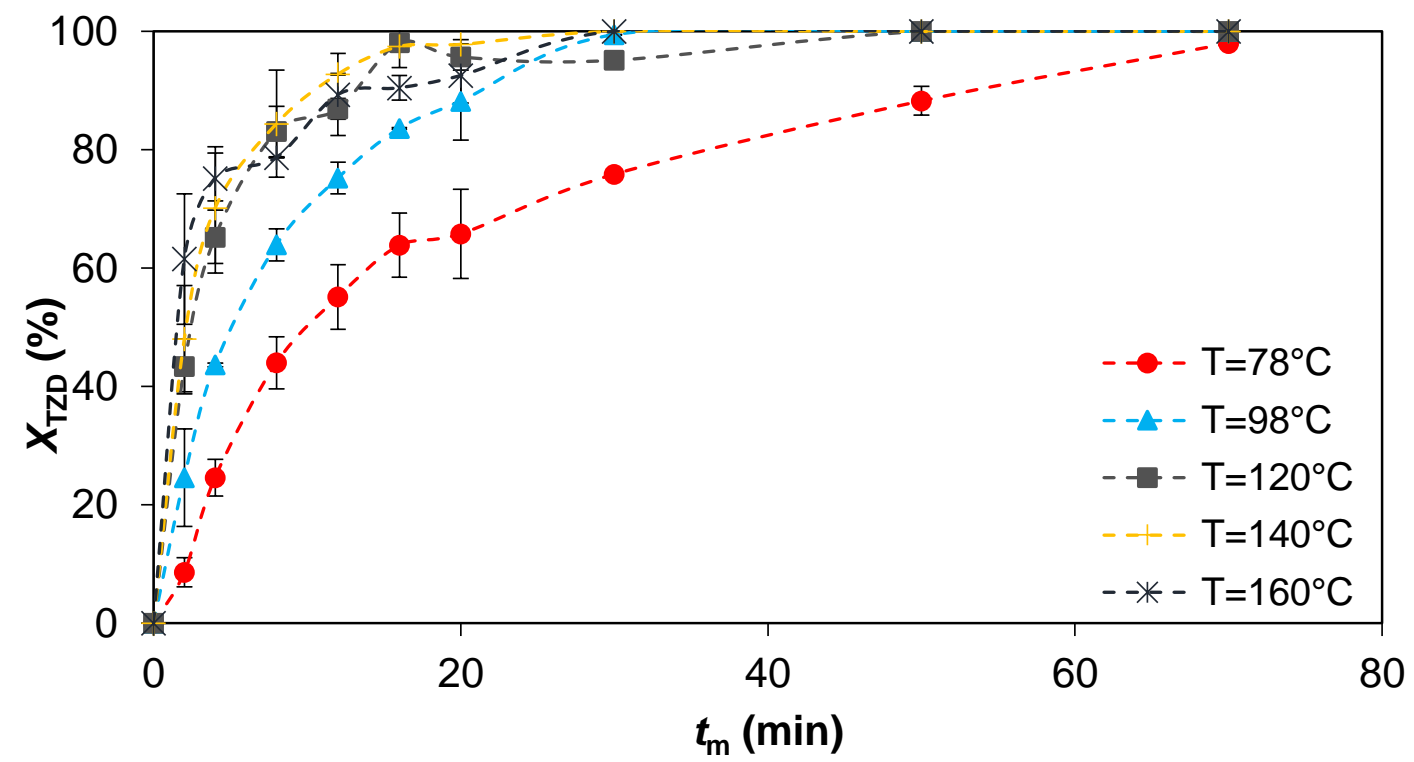

Figure 6. TZD conversion obtained from continuous microreactor process. Solvent: ethanol. Base: pyrrolidine, $0.033 \mathrm{M}$.

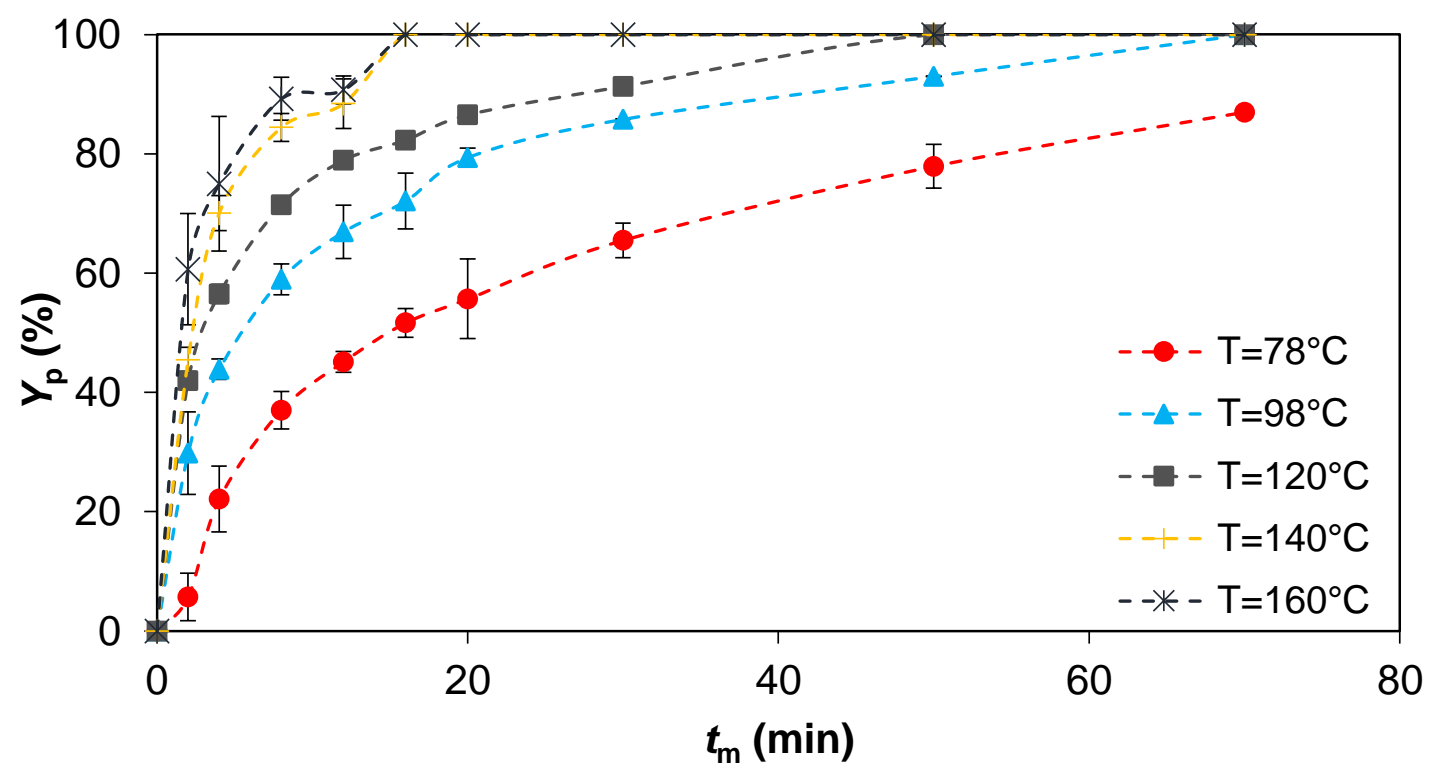

Figure 7. Reaction yield obtained from continuous microreactor process. Solvent: ethanol. Base: pyrrolidine, $0.033 \mathrm{M}$

From Figure 6 was observed that the increment on conversion were not significant for temperatures above $140{ }^{\circ} \mathrm{C}$, reaching $100 \%$ for $t_{\mathrm{m}}=16 \mathrm{~min}$. Nearly complete conversions were observed for all temperatures for residence times longer 
than $16 \mathrm{~min}$, namely, 70, 30, 18, 30 and $30 \mathrm{~min}$ at $78,98,120,140$ and $160{ }^{\circ} \mathrm{C}$, respectively. Figure 7 shows that reaction yield increased with temperature up to $140{ }^{\circ} \mathrm{C}$ and further temperature slightly affected the yield.

Accordingly, it can be highlighted the superior results obtained with pyrrolidine in TZD conversion and reaction yield, regarding the use of piperidine, whereupon a complete conversion was not achieved.

\subsubsection{Comparison between batch reactor and microreactor}

In order to transpose the synthesis from batch to continuous flow microreactor and to verify the advantages of microdevices and the feasibility the continuous synthesis, reaction yield was compared. Figure 8 present the reaction yield for processing time of 0 to $20 \mathrm{~min}$ using piperidine at $78{ }^{\circ} \mathrm{C}$ (batch reactor and microreactor) and $140{ }^{\circ} \mathrm{C}$ (microreactor). In the Supplementary Information, the results for these operating conditions until 480 min for the batch process are given in Figures S8 and S9 (Section S.7).

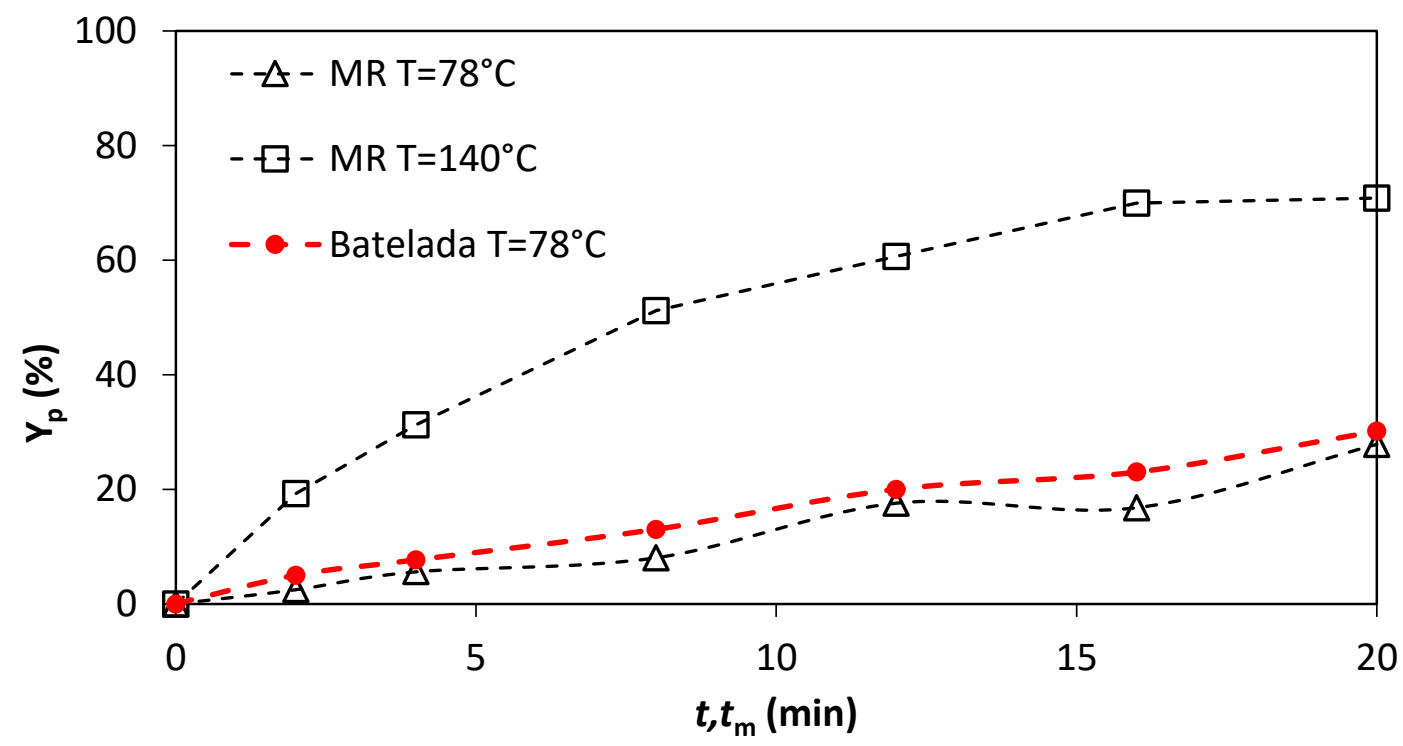


Figure 8. Comparison of product yield obtained in batch reactor and microreactor continuous processing. Base: piperidine, $0.053 \mathrm{M}$. Solvent: ethanol. $t=$ batch processing time; $t_{m}=$ mean residence time in the microreactor (MR).

From Figure 8 was noticed similar reaction yield by both reactors at $78{ }^{\circ} \mathrm{C}$, highlighting a similar efficiency between the two devices, however, the microreactor possesses a volume 30 times smaller, resulting in a significant process intensification related to the physical space required. Another advantage of the microdevice is the possibility of safety operation in elevated temperatures, as noticed at $140{ }^{\circ} \mathrm{C}$, with the superior performance for a residence time of $20 \mathrm{~min}$, achieving a reaction yield of $71 \%$.

A hypothesis to explain the similar performance of the microreactor to the batch reactor at $78{ }^{\circ} \mathrm{C}$ is related to the reaction controlling regime. Despite the advantages of favored diffusion and enhanced heat and mass transfer rates, it was reported that microreactor support better fast reactions, with half-life about seconds [29]. The TZD reaction with p-methoxybenzaldehyde is a slower reaction, with half-life above $10 \mathrm{~min}$, consequently, reaction kinetics controls the process over the mass diffusion. However, the microreactor provides advantages of safety and product quality [30], allowing the operation under higher temperatures and superior product yield.

The results of reaction yield in MBT synthesis with base pyrrolidine are provided in Figure 9 for processing time up to $70 \mathrm{~min}$ at 78 and $140{ }^{\circ} \mathrm{C}$ (microreactor) and $78{ }^{\circ} \mathrm{C}$ (batch reactor). 


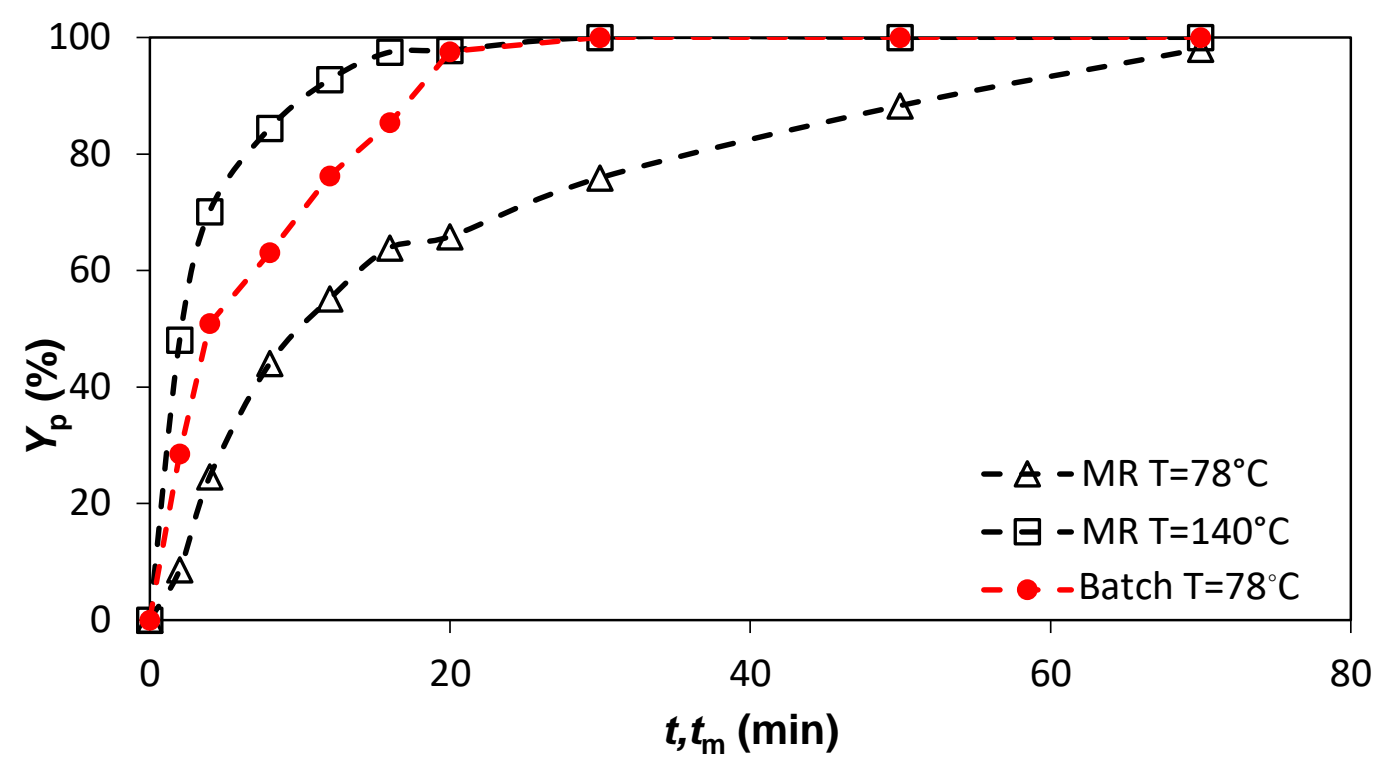

Figure 9. Comparison of product yield obtained in batch reactor and microreactor continuous processing. Base: pyrrolidine, 0.033 M. Solvent: ethanol. $t=$ batch processing time; $t_{m}=$ mean residence time in the microreactor (MR).

The results presented in Figure 9 show that microreactor exhibited an inferior performance at $78{ }^{\circ} \mathrm{C}$. The batch reactor achieved $100 \%$ of reaction yield after $30 \mathrm{~min}$, while the microreactor provided $98 \%$ at $t_{m}=70 \mathrm{~min}$. According to Bogdan et al. [29], this behavior can be attributed to the kinetic controlling regime, since microreactor is very efficient for fast reactions, unlike the MBT synthesis. However, the possibility of operating conditions above the normal boiling point due to the pressure system with easy and safe control, the reaction could be performed at $140{ }^{\circ} \mathrm{C}$, the considered optimal for MBT synthesis, achieving a product yield of $100 \%$ in a more efficient way than batch reactor. In the microreactor, the maximum product yield was obtained for $t_{m}=16$ $\min$ at $140{ }^{\circ} \mathrm{C}$. Also, the initial generation rate of MBT was higher in the microreactor.

\subsubsection{Production rate and number of microreactors}

The production rate of both processes was obtained to complete the comparison between conventional batch and microscale continuous synthesis. Also, this result was 
used to complete the information to evaluate the feasibility of microreactors use in industrial scale. Accordingly, the number equivalent microreactors, $\mathrm{n}^{\circ} \mathrm{MR}$, defined as the number of microreactor units, associated in parallel, required to achieve the same production rate (product mass amount per batch processing time). Figure 10 presents the production rate and the number of equivalent microreactors, for the synthesis using solvent ethanol, batch reactor volume of $60 \mathrm{~mL}$ and batch time of $480 \mathrm{~min}$, with piperidine.

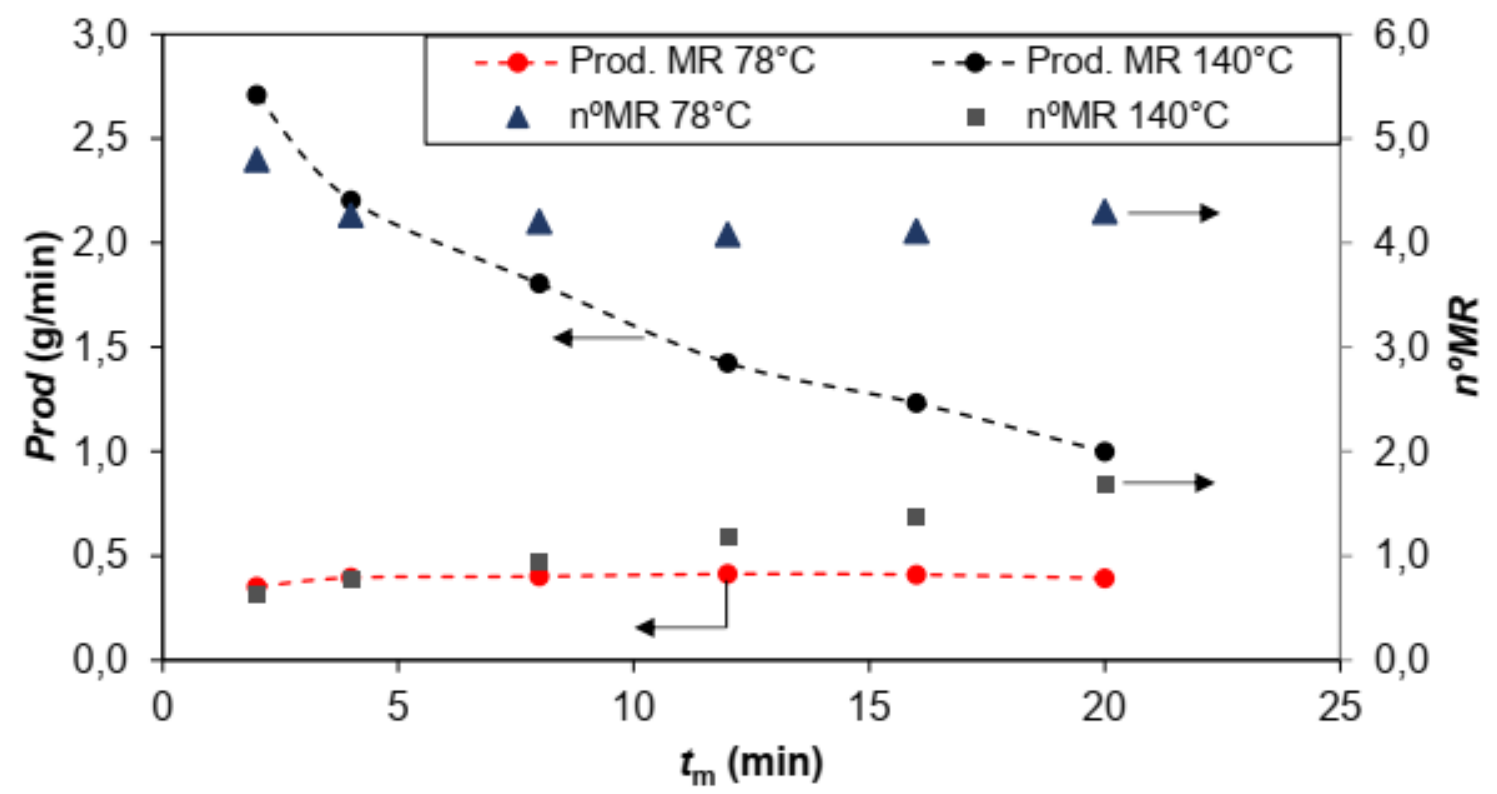

Figure 10. Production rate (Prod) and number of equivalent microreactors ( $\left.n^{\circ} \mathrm{MR}\right)$ : Prod. MR $78{ }^{\circ} \mathrm{C}=$ production rate from microreactor at $78{ }^{\circ} \mathrm{C}$; Prod. $\mathrm{MR} 140{ }^{\circ} \mathrm{C}=$ production rate from microreactor at $140{ }^{\circ} \mathrm{C} ; \mathrm{n}^{\circ} \mathrm{MR} 78{ }^{\circ} \mathrm{C}=$ number of microreactors required to achieve similar production of the batch reactor at $78{ }^{\circ} \mathrm{C} ; \mathrm{n}^{\circ} \mathrm{MR} 140{ }^{\circ} \mathrm{C}=$ number of microreactors required to achieve similar production of the batch reactor at $140{ }^{\circ} \mathrm{C}$. Base: piperidine, $0.053 \mathrm{M}$.

Figure 10 shows that the production rate in microreactor at $78{ }^{\circ} \mathrm{C}$ was virtually constant, about $0.413 \mathrm{~g} \mathrm{~min}^{-1}$, for all range of residence time. However, at $140{ }^{\circ} \mathrm{C}$, the production rate decreased with increment of residence time, being $2.71 \mathrm{~g} \mathrm{~min}^{-1}$ for $t_{m}=$ 
$2 \mathrm{~min}$ and $1.00 \mathrm{~g} \mathrm{~min}^{-1}$ for $t_{m}=20 \mathrm{~min}$. This behavior can be attributed to the product generation rate is greater in the beginning of the process, i.e., the generation rate decreases with time.

The parameter $\mathrm{n}^{\circ} \mathrm{MR}$ presents opposite behavior with production rate, since at higher production rates a smaller number of microreactor units would be required. Once the production rate was almost constant at $78^{\circ} \mathrm{C}, \mathrm{n}^{\circ} \mathrm{MR}$ followed the same tendency. At $78^{\circ} \mathrm{C}, 5$ microreactors arranged in parallel would be required to achieve the production of a batch. At $140{ }^{\circ} \mathrm{C}, \mathrm{n}^{\circ} \mathrm{MR}$ increased with residence time. For $t_{\mathrm{m}}=2 \mathrm{~min}$ a single microreactor resulted in larger production than the batch reactor, while, for $t_{\mathrm{m}}=20 \mathrm{~min}$, two MRs arranged in parallel would be required.

Also, a long run test was carried out in the continuous microreactor, aiming to testify the process stability for a long and permanent regime along $480 \mathrm{~min}$. The long run test was performed at $120^{\circ} \mathrm{C}$ with a residence time of $20 \mathrm{~min}$, using solvent ethanol and pyrrolidine. The result of this run is presented in Figure S10. After 35 min of run, the product yield reached $95 \%$, becoming stable until $480 \mathrm{~min}$, showing the capability of the microreactor for long run continuous operation.

Finally, an extensive product characterization was performed by analyses of melting point, FT-IR, NMR ${ }^{1} \mathrm{H}$ and ${ }^{13} \mathrm{C}$, to determine the product purity. Details of these procedures and its results are provided in Supplementary Information, Section S9.

\subsubsection{Chemical kinetics and thermodynamic parameters}

The reaction order of reactants TZD and p-methoxybenzaldehyde were determined using the excess method. The obtained kinetic model was used in the numerical simulation. The kinetic rate equation was mathematically treated according to the first order model described in [31]. Figures 11 and 12 show the results of kinetic analysis for TZD and aldehyde, respectively. 


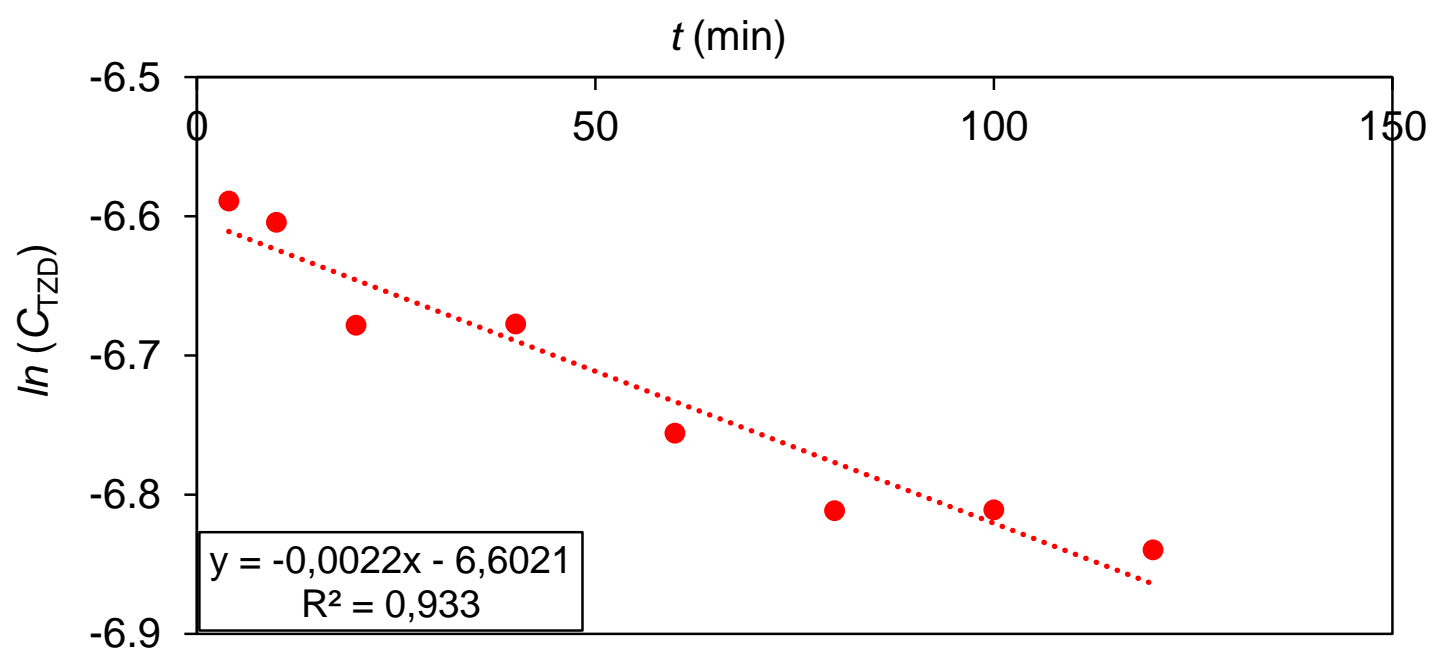

Figure 11. Determination of reaction order for TZD. First order kinetics with excess of aldehyde. Solvent-free, TZD 0.067 M in p-methoxybenzaldehyde, pyrrolidine 0.033 M.

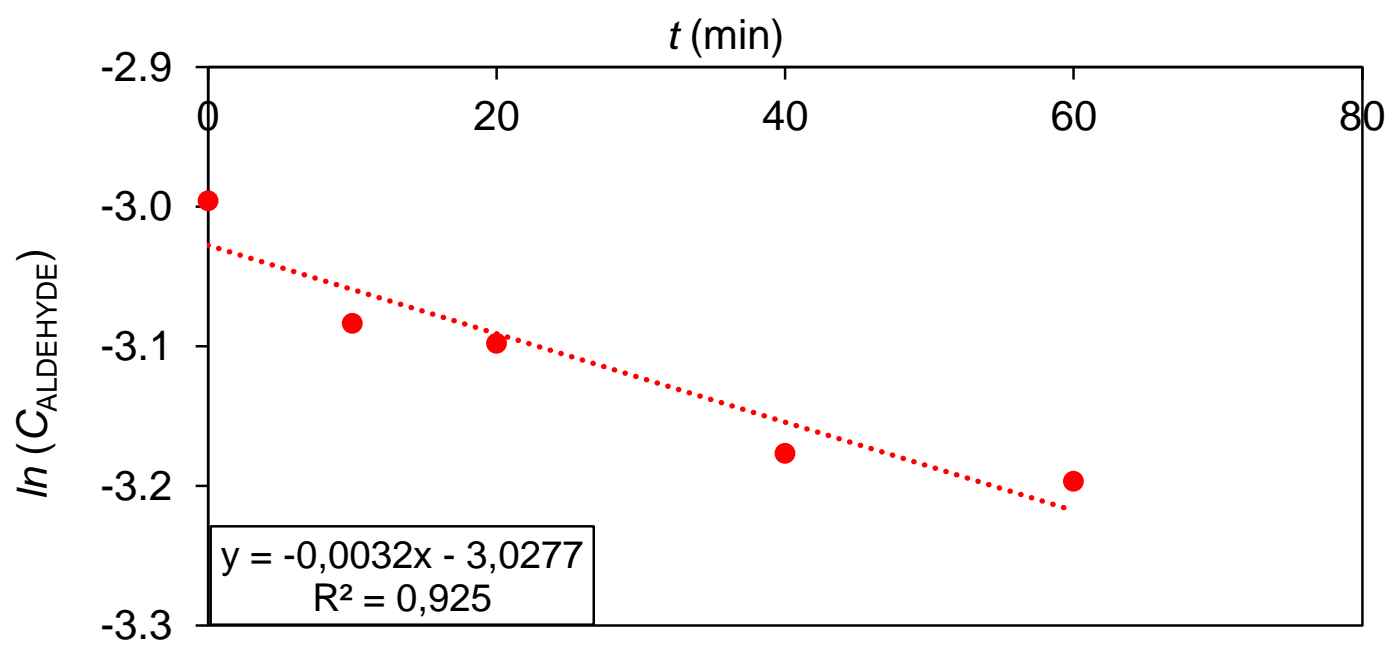

Figure 12. Determination of reaction order for $\mathrm{p}$-methoxybenzaldehyde. First order kinetics with excess of TZD. Solvent ethanol, TZD $0.067 \mathrm{M}$, p-methoxybenzaldehyde $0.0033 \mathrm{M}$, base pyrrolidine.

Figure 11 demonstrated a good agreement between the mathematical model to the experimental data with a $\mathrm{R}^{2}=0.933$, proving the first order dependence on TZD concentration. Also, for the aldehyde, the first order mathematical model presented good agreement with kinetic data $\left(\mathrm{R}^{2}=0.925\right)$, as seen in Figure 12. Accordingly, a first 
order kinetic model for individual reactant species was considered and consequently a second order model for the global reaction. The second order global model was used to determine the kinetic constant $(k)$ at each temperature $\left(78,98,120,140\right.$ and $\left.160{ }^{\circ} \mathrm{C}\right)$ for piperidine and pyrrolidine [32]. The $k$ values are summarized in Table 3.

Table 3. Reaction rate constant, $k\left(\mathrm{M}^{-1} \mathrm{~s}^{-1}\right)$, for a second order global reaction at different temperatures for solvent ethanol and promoter bases piperidine $(0.053 \mathrm{M})$ and pyrrolidine $(0.033 \mathrm{M})$.

\begin{tabular}{ccc}
\hline$T\left({ }^{\circ} \mathrm{C}\right)$ & \multicolumn{2}{c}{$k \times 10^{2}\left(\mathrm{M}^{-1} \mathrm{~s}^{-1}\right)$} \\
& Piperidine & Pyrrolidine \\
\hline 78 & 0.718 & 1.70 \\
98 & 1.02 & 3.51 \\
120 & 1.95 & 6.07 \\
140 & 4.05 & 18.3 \\
160 & 5.03 & 22.9 \\
\hline
\end{tabular}

From results of Table 3 was observed an increment on reaction rate constant with temperature. The $k$ values for pyrrolidine were always higher than piperidine, corresponding to the previously observed since pyrrolidine exhibited a superior performance achieving maximum conversion and product yield with shorter processing times. The activation energy, $E_{a}$, was determined from the reaction rate constant, $k$. Subsequently, thermodynamic parameters of transition state were also estimated: entalphy variation $\left(\Delta H^{*}\right)$, entropy variation $\left(\Delta S^{*}\right)$ and Gibbs free energy variation $\left(\Delta G^{*}\right)$, according to the mathematical treatment described in Section 2.2.3. The results are summarized in Table 4. 
Table 4. Activation energy, $E_{a}$, and thermodynamic parameters of transition state, $\Delta H^{*}$, $\Delta S^{*}$ and $\Delta G^{*}$, estimated for promoter bases piperidine $(0.053 \mathrm{M})$ and pyrrolidine $(0.033$ M).

\begin{tabular}{c|cccccc}
\hline \multirow{2}{*}{} & \multicolumn{2}{|c}{$E_{a}(\mathrm{~kJ} / \mathrm{mol})$} & \multicolumn{2}{c}{$\Delta H^{*}(\mathrm{~kJ} / \mathrm{mol})$} & \multicolumn{2}{c}{$\Delta S^{*}(\mathrm{~kJ} / \mathrm{mol} \mathrm{K})$} \\
Solvent: & Piperidine & Pyrrolidine & Piperidine & Pyrrolidine & Piperidine & Pyrrolidine \\
\cline { 2 - 7 } Ethanol & 37.3 & 34.7 & 34.1 & 31.6 & -0.197 & -0.197 \\
\cline { 2 - 7 } & Base & $78^{\circ} \mathrm{C}$ & $98^{\circ} \mathrm{C}$ & $120^{\circ} \mathrm{C}$ & $140^{\circ} \mathrm{C}$ & $160^{\circ} \mathrm{C}$ \\
& Piperidine & 103.2 & 107.1 & 111.5 & 115.4 & 119.4 \\
& Pyrrolidine & 108.6 & 112.5 & 116.8 & 120.6 & 124.5 \\
\hline
\end{tabular}

The activation energy of pyrrolidine was lower than $E_{a}$ of piperidine (Table 4). Similar behavior was noticed for $\Delta H^{*}$. The entropy variation estimated was equal for the two promoter bases. These results corroborates with the superior performance of MBT synthesis (conversion, yield and initial generation rate) achieved with pyrrolidine.

The variations of Gibbs free energy were obtained from $\Delta H^{*}$ and $\Delta S^{*}$ values and were also listed in Table 4 for piperidine and pyrrolidine. The $\Delta G^{*}$ values were positive for all temperatures for both promoter bases. These results indicate that the reaction between TZD and p-methoxybenzaldehyde is not spontaneous, demanding a promoter base.

4.3. Numerical simulations of the synthesis of (Z)-5-(4methoxybenzylidene)thiazolidine-2,4-dione (MBT) in the microreactor

The numerical simulation of the reaction between 2,4-thiazolidinedione (TZD) with $\quad$-methoxybenzaldehyde (p-MTB) to produce (Z)-5-(4methoxybenzylidene)thiazolidine-2,4-dione (MBT) in a liquid phase was performed using the kinetic model previously developed, considering pyrrolidine and ethanol as solvent. The simulation were carried out in ANSYS CFX 19, for a temperature range of 
$78-140{ }^{\circ} \mathrm{C}$ and residence times from 2 to $50 \mathrm{~min}$. The numerical predictions of TZD conversion and product yield are shown in Figures 13 and 14, respectively. In general, the conversion and yield increased with temperature, agreeing with experimental results. The maximum conversion and product yield were also achieved at $140{ }^{\circ} \mathrm{C}$.

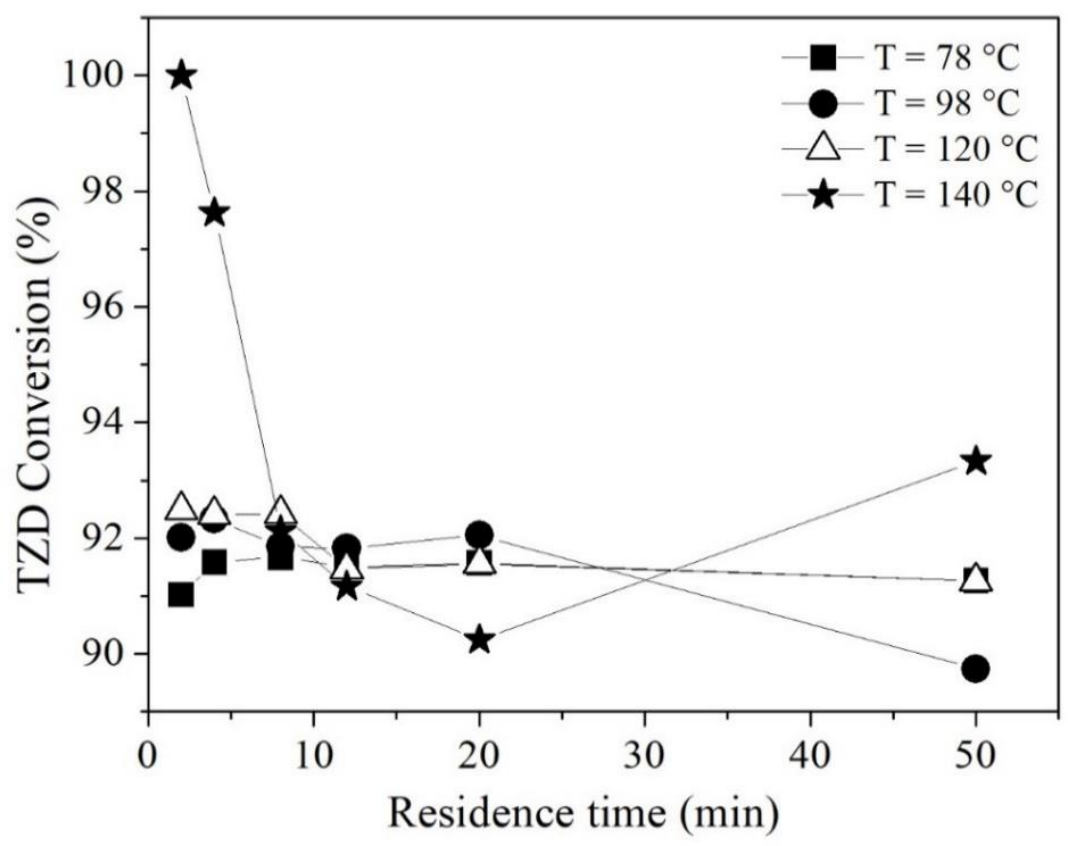

Figure 13. Numerical predictions of temperature effect on TZD conversion as a function of residence time.

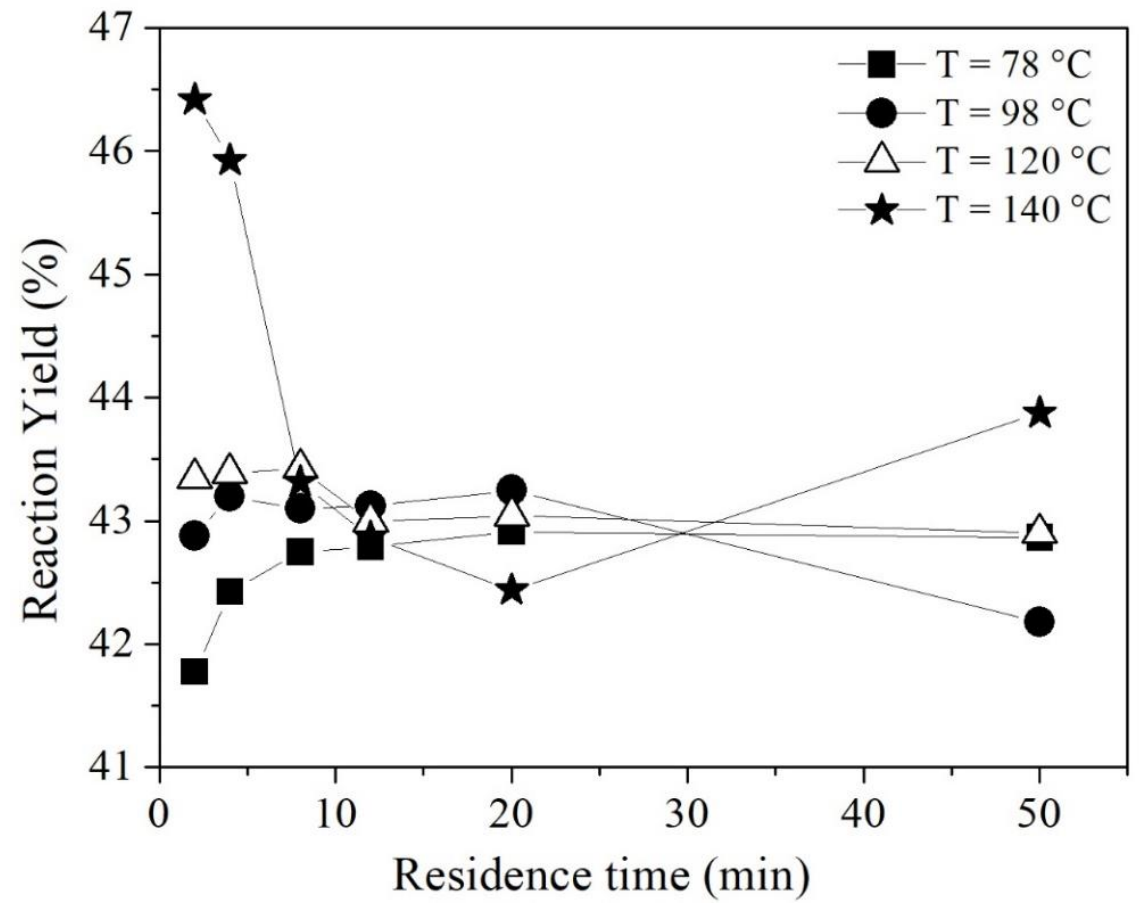


Figure 14. Numerical predictions of temperature effect on reaction yield as a function of residence time.

Table 5. Estimated deviations between experimental and numerical approaches on TZD conversion at $140{ }^{\circ} \mathrm{C}$. Pyrrolidine $0.033 \mathrm{M}$ in ethanol.

\begin{tabular}{cccc}
\hline $\boldsymbol{t}_{\boldsymbol{m}}$ (min) & $\begin{array}{c}\text { Experimental } \\
\text { result (\%) }\end{array}$ & $\begin{array}{c}\text { Numerical } \\
\text { prediction }(\boldsymbol{\%})\end{array}$ & $\begin{array}{c}\text { Deviation } \\
(\boldsymbol{\%})\end{array}$ \\
\hline 2 & 45.45 & 100 & 120.02 \\
4 & 70.07 & 97.62 & 39.33 \\
8 & 84.42 & 92.12 & 9.13 \\
12 & 88.42 & 91.16 & 3.11 \\
20 & 100 & 90.24 & -9.76 \\
50 & 100 & 93.34 & -6.66 \\
\hline
\end{tabular}

By the numerical results was observed a decrease on conversion and reaction yield with increment of residence time at $140^{\circ} \mathrm{C}$ and were virtually constant at other temperatures, which disagreed with experimental observations. A consistent evaluation demonstrates that despite the maximum conversion was achieved at $140{ }^{\circ} \mathrm{C}$ in both approaches, experimental and numerical, the influence of residence time in the synthesis was different in such evaluations. In experimental approach, the conversion and product yield achieved their maximum at $140{ }^{\circ} \mathrm{C}$ for a residence time of $12 \mathrm{~min}$ (Figure 6 and 7). In contrast, the numerical approach predicted a maximum conversion for a residence time of 2 min. Also, the conversion decreased with increment on residence time up to a minimum at $20 \mathrm{~min}$. The absolute deviation between numerical and experimental were $9.76 \%\left(t_{m}=20 \mathrm{~min}\right)$ and $3.11 \%$ for $t_{m}=12 \mathrm{~min}$, as summarized in Table 5. However, the computational model still cannot reproduce the reaction yield, resulting in deviations above to $33 \%$ from experimental data.

The results presented in Figure 13 and 14 and Table 5 were similar to data from Figure 13, showing a decrease on production rate of microreactor with the increment on 
residence time, being $2.71 \mathrm{~g} \mathrm{~min}^{-1}$ for $t_{m}=2 \mathrm{~min}$ and $1.00 \mathrm{~g} \mathrm{~min}^{-1}$ for $t_{m}=20 \mathrm{~min}$. This behavior was explained based on the generation rate at the beginning of reaction process. Analogue behavior can be occurring on the numerical model. This hypothesis needs further investigations and the mathematical model demands improvements. These features are a future goal of our research group.

\section{Conclusion}

The MBT synthesis from the chemical reaction between 2,4-Thiazolidinedione with p-Methoxybenzaldehyde using ethanol as solvent, was evaluated from the conventional batch process and transposed to continuous microreactor. Experimental (batch reactor and microreactor) and numerical (microreactor) approaches were used. Firstly, a study of promoter base was performed in the batch process. Pyrrolidine $(0.033$ M) exhibited the superior performance for product yield and initial reaction rate, proving its potentiality to replace piperidine on synthesis. The studied synthesis did not required long processing times $(35-40 \mathrm{~h})$ to achieve stability and maximum yield on batch reactor, as found in literature. The maximum yield was achieved after 180 and 480 min with pyrrolidine and piperidine, respectively. The promoter base concentration was optimized for piperidine and pyrrolidine, providing optimal values of $0.053 \mathrm{M}$ and $0.033 \mathrm{M}$, respectively. The continuous microreactor synthesis provided superior yield regarding the batch reactor at specific temperature and residence time. An equivalence of reactors performance was observed at solvent normal boiling point $\left(78^{\circ} \mathrm{C}\right)$. This was attributed to microreactors favor fast reactions, with half-life about few seconds, while, MBT synthesis presents a half-life above $10 \mathrm{~min}$, consequently, is controlled by chemical kinetics instead of mass diffusion. However, with the safety control of temperature and pressure, the microdevice provided superior performance in higher 
temperatures. The long run continuous process using the microreactor showed operational stability along the $8 \mathrm{~h}$, highlighting the capacity of microreactors usage in long steady-state operations. At $78{ }^{\circ} \mathrm{C}$, the microreactor produced a virtually constant rate of $0.413 \mathrm{~g} \mathrm{~min}^{-1}$ of MBT. At $140{ }^{\circ} \mathrm{C}$ and a residence time of $t_{\mathrm{m}}=2 \mathrm{~min}$, the production rate of $2.71 \mathrm{~g} \mathrm{~min}^{-1}$ was noticed, while the batch process resulted in $1.69 \mathrm{~g}$ $\min ^{-1}$ (considering a $8 \mathrm{~h}$ run). Accordingly, a single microreactor operating at $140{ }^{\circ} \mathrm{C}$ and $t_{\mathrm{m}}=2$ min provide a higher product throughput regarding the batch reactor. The synthesized MBT (5-(4-methoxybenzylidene)-2,4-thiazollidinedione) was verified by the analytical techniques of melting point, FT-IR, ${ }^{1} \mathrm{H}$ NMR and ${ }^{13} \mathrm{C}$ NMR, resulting in a purity level of $99.7 \%$ mol. as determined by DSC analysis.

After the process performance evaluation, the chemical kinetics and thermodynamics parameters were obtained. A first order model agreed with experimental data for both reactants, resulting in a second order global reaction rate expression. Reaction rate constant, activation energy and the variations of enthalpy, entropy and Gibbs free energy were determined for the promoter bases piperidine and pyrrolidine. All the estimated variations of Gibbs free energy were positive, proving the non-spontaneity of the synthesis, corroborating with the fundamental role of the promoter base.

The kinetic expression obtained from experimental data was employed in the numerical simulations. In general, the numerical predictions showed an increment on conversion and yield with temperature, agreeing with experiments. The maximum conversion and yield were obtained at $140{ }^{\circ} \mathrm{C}$ for both approaches, experimental and numerical. The maximum conversion was predicted by numerical simulation for $2 \mathrm{~min}$ of residence time and the smaller deviation between simulations and experiments was 
$3.10 \%$. However, the mathematical model still cannot represent well the reaction yield with deviations above $33 \%$ and requires further improvement.

Based on the presented results, the continuous process using microreactor were a feasible alternative to batch process for MBT synthesis. Still, microreactor technology needs to be widespread in chemical and pharmaceutical industries, since it can often allow improved safety process, superior product selectivity and yield, lower residue throughput and also occupy smaller industrial areas.

\section{Acknowledgements}

The authors would like to thank the financial support provided by $\mathrm{CNPq}$ (National

Council for Scientific and Technological Development, Process 404760/2016-3) and FAPESP (São Paulo Research Foundation, Process 2014/07757-2, Process 2016/208424).

\section{References}

[1] K.V. Gernaey, A.E., Cevera-Padrell, J.M. Woodley, Comp. Chem. Eng. 42 (2012) 15-29. https://doi.org/10.1016/j.compchemeng.2012.02.022

[2] H.S. Santana, D.S. Tortola, E.M. Reis, J.L. Silva, O.P. Taranto, Chem. Eng. J. 302 (2016) 752-762. https://doi.org/10.1016/j.cej.2016.05.122

[3] J.I. Yoshida, Y. Takahashi, A. Nagaki, Chem. Commun. 49 (2013) 98969904.https://doi.org/10.1039/C3CC44709J

[4] M.G.M. Lopes, H.S. Santana, V.F. Andolphato, F.N. Russo, J.L. Silva Jr., O.P. $\begin{array}{llllll}\text { Taranto, } & \text { Energ. } & \text { Conv. } & \text { Manage. } & 184 & \text { (2019) }\end{array}$ https://doi.org/10.1016/j.enconman.2019.01.090

[5] C. Wiles, P. Watts, Chimica Oggi/Chem. Today, 28, June (2010) 3-5.

[6] C. Wiles, P. Watts,. Green Chem. 14 (2012) 38-54. https://doi.org /10.1039/C1GC16022B

[7] H. B. Ammar, M. Chtourou, M. H. Frikha, M. Trabelsi. Ultrason Sonochem. 22 (2015) 559-564. https://doi.org/10.1016/j.ultsonch.2014.07.018

[8] S. Mohanty, S.G. Reddy, B. Ramadevi, A.C. Karmakar, Med. Chem. Res., 24 (2015) 4037-4049. https://doi.org/10.1007/s00044-015-1447-0

[9] G. Mishra, N. Sachan, P. Chawla, Lett. Org. Chem. 12 (2015) 429-445, 2015. https://doi.org/10.2174/1570178612666150424235603 
[10] M. Baumann, I.R. Baxendale, Beilstein J. Org. Syn. 11 (2015) 1194-1219. https://doi.org/10.3762/bjoc.11.134

[11] M.G.M. Lopes, H.S. Santana, V.F. Andolphato, F.N. Russo, J.L. Silva Jr., O.P. Taranto, Chem. Eng. Res. Des. $138 \quad$ (2018) 458-471. https://doi.org/10.1016/j.cherd.2018.09.011

[12] J. Melo, Usinas de Biodiesel em Pernambuco. https://www.biodieselbr.com/noticias/colunistas/convidado/usinas-biodieselpernambuco-300410.htm, 2017. (acessed 15 November 2019)

[13] H.S. Santana, D.S. Tortola, J.L. Silva, O.P. Taranto, Energ. Conv. Manage. 141 (2017) 28-39. https://doi.org/10.1016/j.enconman.2016.03.089

[14] H.S. Santana, J.L. Silva, O.P. Taranto, Sens. Act. B: Chem. 281 (2019) 191-203, 2019. https://doi.org/10.1016/j.snb.2018.10.089

[15] D.S. Pinheiro, R.R.O. Silva, P.V.C. Calvo, M.F. Silva, A. Converti, M.S.A. Palma. Chem. Eng. Tech. 41 (2018) 1800-1807. https://doi.org/10.1002/ceat.201800189

[16] D.S. Pinheiro, E.N.S. Junior, G. Consolini, M.J. Aguiar, R.R.O. Silva, R.O. Vieira, M.S.A. Palma. MOJ Bioorg. Org. Chem. 1 (2017) 1-5. https://doi.org/10.15406/mojboc.2017.01.00022

[17] P. Harriott, Chemical Reactor Design, Marcel Dekker, New York, 2003.

[18] C. G. Hill, Jr, T. W. Root, Introduction to Chemical Engineering Kinetics and Reactor Design, John Wiley \& Sons, United State of America, 2014.

[19] Syrris, Asia Microreactors Datasheet, Technical Note. 2012. https://syrris.com/wpcontent/uploads/2017/08/Asia-Tech-Sup-Note-Microreactors-datasheet-CUSTOMER-

RELEASE.pdf. (Acessed 02 December 2019)

[20] H.S. Santana, J.L. Silva, O.P. Taranto, Chem. Eng. Sci. 132 (2015) 159-168. https://doi.org/10.1016/j.ces.2015.04.014

[21] R.B. Bird, W.E. Stewart, E.N. Lightfoot, Transport Phenomena, John Wiley \& Sons, United State of America, 2002.

[22] G. Bruno, L. Costantino, C. Curinga, R. Maccari, F. Monforte, F. Nicolo, R. Ottana, F. Vigorita, Bioorg. Med. Chem. $10 \quad$ (2002) 1077-1084. https://doi.org/10.1016/s0968-0896(01)00366-2

[23] B.R.P. Kumar, M. Soni, S.S. Kumar, K. Singh, M. Patil, R.B.N. Baig, L. Adhikary, Eur. J. Med. Chem. 46 (2011) 835-844. https://doi.org/10.1016/j.ejmech.2010.12.019

[24] S.K.Shyam, R. Sandeep, S. Sowjanya, J.C. Spandana, A. Srinivas, Int. J. Pharm. Scie. Rev. Res. 22 (2013) 23-29.

[25] Y. Momose, K. Meguro, H. Ikeda, C. Hatanaka, S. Oi, T. Sohda, Chem. Pharm. Bulletin, 39 (1991) 1440-1445. https://doi.org/10.1248/cpb.39.1440

[26] K.F. Jensen, AIChE Journal, 63 (2017) 858-869. http://doi.org/10.1002/aic.15642

[27] N. Zaborenko, M.W. Bedore, T.F. Jamison, K.F. Jensen, Organic Process Research \& Development, 15 (2011) 131-139. http://doi.org/10.1021/op100252m

[28] E.S. Siguemoto, L.L. Reche, J.A.W. Gut, M.S.A. Palma. Chem. Eng. Tech., 43 (2019), 429-435. https://doi.org/10.1002/ceat.201900478

[29] A.R. Bogdan, S.L. Poe, D.C. Kubis, S.J. Broadwater, D.T. Mcquade, Angew. Chem. Int. Edit. 48 (2009) 8547-8550. https://doi.org/10.1002/anie.200903055 
[30] D.M. Roberge, L. Ducry, N. Bieler, P. Cretton, B. Zimmerman, Chem. Eng. Technol. 28 (2005) 318-323. https://doi.org/10.1002/ceat.2004071

[31] J.E. House, Principles of Chemical Kinetics, 2nd. Ed, 2007, 337p., Academic Press, Elsevier, Burlington, MA, USA.

[32] O. Levenspiel, Chemical Reaction Engineering, 3rd. Ed., John Wiley \& Sons, Inc., Hoboken, New Jersey, 1999, p. 321 - 338. 